\title{
Conserved and divergent development of brainstem vestibuloacoustic nuclei
}

\author{
Marcela Lipovsek ${ }^{1}$ and Richard JT Wingate ${ }^{1,2}$
}

1. Centre for Developmental Neurobiology, King's College London, Institute of Psychiatry, Psychology and Neuroscience, Guy's Campus, London SE1 1UL

2. MRC Centre for Neurodevelopmental Disorders, King's College London, Institute of Psychiatry, Psychology and Neuroscience, Guy's Campus, London SE1 1UL

Correspondence should be addressed to Marcela Lipovsek (marcela.lipovsek@kcl.ac.uk) 


\section{ABSTRACT}

Vestibular function was established early in vertebrates and has remained, for the most part, unchanged. In contrast, tetrapods underwent independent evolutionary processes to solve the problem of hearing on land. Thus, the vestibuloacoustic nuclei of the hindbrain provide an ideal framework on which to address the participation of developmental processes to the evolution of neuronal circuits.

We employed an electroporation strategy to unravel the contribution of dorsoventral and axial lineages to the development of the chick hindbrain vestibular and auditory nuclei. We compare the chick developmental map with recently stablished genetic fate-maps of the mouse hindbrain. Overall, we find considerable conservation of developmental origin for the vestibular nuclei. In contrast, auditory hindbrain development echoes the complex evolutionary history of the auditory system. In particular, we find that the developmental origin of a chick sound localisation circuit supports its emergence from an ancient vestibular network, unrelated to the analogous mammalian counterpart. 
bioRxiv preprint doi: https://doi.org/10.1101/372243; this version posted July 18, 2018. The copyright holder for this preprint (which was not certified by peer review) is the author/funder, who has granted bioRxiv a license to display the preprint in perpetuity. It is made available under aCC-BY-NC-ND 4.0 International license.

\section{Introduction}

The colonisation of land by tetrapods led to a series of independent solutions to the problem of adapting sensory systems from water to air. In particular, the auditory apparatus was modified several times through a mixture of alteration of ancestral structures and de novo innovations (Chagnaud et al., 2017; Fritzsch and Elliott, 2017; Fritzsch and Straka, 2014; Grothe and Pecka, 2014; Manley, 2000, 2017). These changes also required the evolution of associated neural processing networks in the hindbrain. Each extant neural circuit is therefore an elaboration of the remarkably conserved brainstem groundplan (Nieuwenhuys, 2011) and has been resourced from a repertoire of neural lineages that depicts an ancestral rhombomeric arrangement (Philippidou and Dasen, 2013; Wullimann et al., 2011).

The interplay between ancestral and de novo responses to changing environmental context is readily apparent when comparing the auditory and vestibular systems, which have interrelated developmental and evolutionary histories (Duncan and Fritzsch, 2012; Fritzsch and Straka, 2014; Manley et al., 2004). Both systems process mechanical stimuli and share an ancestral receptor cell type (the hair cells), which sit in specialised sensory epithelia located in the inner ear and develop from the same ectodermal thickening, the otic placode (Fritzsch and Elliott, 2017; Fritzsch and Straka, 2014; Whitfield, 2015). Vestibular sensory input has remained mostly unchanged and, correspondingly, vestibular peripheral organs, hindbrain vestibular nuclei and their projection patterns are highly conserved across vertebrates (Straka and Baker, 2013; Straka et al., 2014). All vertebrates possess a conserved set of vestibular sensory epithelia that project, via the eighth nerve, to a conserved set of hindbrain vestibular structures: superior, lateral (or Deiters), medial and descending (inferior or spinal) vestibular nuclei (Figure 1A).

In contrast, the transition from an aquatic to a land environment brought about a marked transformation of the auditory scene and led to various specialisations for the detection of airborne sound (Carr and Christensen-Dalsgaard, 2016; Carr and Soares, 2002; Clack, 2015; Fritzsch and Straka, 2014; Grothe et al., 2004; Grothe and Pecka, 2014; Manley, 2000, 2017). Paleontological, morphological, functional and behavioural evidence suggests that a number of auditory peripheral and central innovations emerged separately in the different clades of land vertebrates (Grothe and Pecka, 2014; Manley, 2000, 2017; Manley et al., 2004). Most striking amongst them is the independent emergence during the Triassic period, more than 100 million years after the separation of the tetrapod lineages, of at least five variants of a tympanic middle ear, which operates as an impedance matching device for the efficient detection of airborne sounds (Anthwal et al., 2013; Carr and Christensen-Dalsgaard, 2016; Clack, 2015; Kitazawa et al., 2015; Manley, 2000; Tucker, 2017). This was accompanied by the independent elongation of the auditory sensory epithelia, a parallel 
bioRxiv preprint doi: https://doi.org/10.1101/372243; this version posted July 18, 2018. The copyright holder for this preprint (which was not certified by peer review) is the author/funder, who has granted bioRxiv a license to display the preprint in perpetuity. It is made available under aCC-BY-NC-ND 4.0 International license.

diversification of hair cell types and concomitant elaborations of hair cell based sound amplification mechanisms, ultimately leading to fine tuning of sound detection and expansions of the hearing range to higher frequencies in several amniote clades (Dallos, 2008; Hudspeth, 2008; Koppl, 2011; Manley, 2000, 2017).

Alongside the independent emergence of middle and inner ear innovations, amniotes have developed neural mechanisms for processing sound stimulus of increasing frequency and accuracy. As a result, the complement of brainstem auditory nuclei, the central targets of the auditory branch of the eighth nerve, varies greatly between clades and no true homologies could be established between them thus far (Carr and Christensen-Dalsgaard, 2016; Grothe et al., 2004). Mammals (the first clade to split from the ancestral amniote branch) possess two first order auditory nuclei, the ventral and dorsal cochlear nuclei. These project to second order hindbrain nuclei: lateral and medial superior olive and lateral and medial nucleus of the trapezoid body, as well as to other brainstem and higher order targets (Carr and Soares, 2002; Grothe et al., 2004) (Figure 1B). In diapsids (reptiles and birds), two first order nuclei receive auditory nerve afferents: the nucleus angularis and nucleus magnocellularis. These project as well to second order hindbrain nuclei (superior olivary nucleus and nucleus lateralis) and higher order structures (Carr and Soares, 2002; Grothe et al., 2004) (Figure 1C). Notwithstanding the presence of such divergent arrays of hindbrain auditory structures, both mammals and archosaurs (birds and crocodilians) have developed mechanisms for sound source localisation based on hindbrain neural processing circuits. Functional analogies and convergent evolution have been proposed for some sub-circuits (Carr and Christensen-Dalsgaard, 2016; Carr and Soares, 2002; Grothe et al., 2010). An example is the interaural time difference (ITD) circuit that compares the difference in time of arrival of sound to each ear to determine the location of the sound source in the horizontal plane. In both mammals and archosaurs the overall organisation of the circuit is similar, with bilaterally projecting first order neurons that converge in coincidence detection neurons that are, in turn, modulated by inhibitory input (Figure 1D,E). However, a number of circuit features reveal that the functional analogy is only superficial and indicate that the ITD circuits are an example of convergent evolution (Carr and Christensen-Dalsgaard, 2016; Carr and Soares, 2002; Grothe et al., 2004; Grothe and Pecka, 2014; Grothe et al., 2010). Although coincidence detection neurons are present in both groups, only the avian connectivity resembles a Jeffres model circuit (Jeffress, 1948) (Figure 1E), with axonal delay lines that contact coincidence detection neurons arranged as a place code (Ashida and Carr, 2011; Grothe et al., 2010). Such a wiring pattern is not present in mammals (Grothe et al., 2010; Karino et al., 2011) (Figure 1D), and the ITD coding strategies differ between the two clades (Grothe and Pecka, 2014; Grothe et al., 
bioRxiv preprint doi: https://doi.org/10.1101/372243; this version posted July 18, 2018. The copyright holder for this preprint (which was not certified by peer review) is the author/funder, who has granted bioRxiv a license to display the preprint in perpetuity. It is made available under aCC-BY-NC-ND 4.0 International license.

2010). Moreover, inhibitory modulation plays different roles in avian and mammalian ITD circuits (Grothe, 2003; Grothe and Pecka, 2014).

The notable disparity between the highly conserved vestibular hindbrain and the independently elaborated auditory hindbrain provides a framework on which to interrogate the contribution of developmental processes to the evolution of neuronal circuits, given that both systems are derived from the ancestral octavolateral column. In particular, to what extent are the respective ITD circuits de novo innovations for processing sound localisation, or a convergent assemblage based on a similar repertoire of ancestral neurons?

To answer these questions, we perform a comparative analysis of the developmental origin of vestibular and hindbrain nuclei. We have exploited recent advances in genetic fate-mapping in chick embryos (Green and Wingate, 2014; Kohl et al., 2012) to compare the origins of avian vestibular and auditory neurons with that recently characterised in mouse (Di Bonito et al., 2013; Di Bonito et al., 2017; Farago et al., 2006; Fujiyama et al., 2009; Marrs and Spirou, 2012; Pasqualetti et al., 2007; Yamada et al., 2007). Specifically we have studied the rhombic lip lineage, characterised by a progenitor pool expressing Atoh1 (Ben-Arie et al., 2000; Machold and Fishell, 2005; Rose et al., 2009; Wang et al., 2005), and a ventricular zone lineage whose precursors express Ptf1a (Meredith et al., 2009; Yamada et al., 2007). These two lineages collectively define the majority of the auditory circuit in mouse, including all first order auditory neurons (Fujiyama et al., 2009). To underpin the Atoh1 and Ptf1a lineage contributions to avian hindbrain vestibular and auditory nuclei we performed an electroporation-based fate-mapping in chick embryos, using enhancer driven reporter constructs. Additionally, we traced their axial origin through the electroporation of reporter constructs driven by enhancer elements from Hoxb1, Egr2 (Krox20), Hoxa3 and Hoxd4.

Our results lend strong support to the hypothesis that vestibular nuclei are developmentally homologous in chick and mouse to a fine level of detail, reflecting the ancestral origin and conservation of these hindbrain structures. By contrast, auditory nuclei show a mixture of conserved and divergent developmental origin. In particular, functionally analogous circuit components in the ITD circuit of the chick and mouse have different lineage contributions supporting a long-held hypothesis that they represent an example of evolutionary convergence. 
bioRxiv preprint doi: https://doi.org/10.1101/372243; this version posted July 18, 2018. The copyright holder for this preprint (which was not certified by peer review) is the author/funder, who has granted bioRxiv a license to display the preprint in perpetuity. It is made available under aCC-BY-NC-ND 4.0 International license.

\section{Results}

In order to determine the developmental origin of hindbrain auditory and vestibular nuclei, we performed in ovo electroporation of chick embryos at stages 12 to 14 (Figure 2A) with two contrasting sets of conditional reporter constructs. First, we used enhancer elements from the bHLH transcription factors Atoh1 (Helms et al., 2000; Kohl et al., 2012) and Ptf1a (Meredith et al., 2009), which are expressed in distinct dorsoventrally located neuronal progenitors (Figure 2B). Electroporation with Atoh1-Cre + Stop-GFP + CAGGS mCherry (Figure 2C) or Ptf1a-Cre + PBase +PbStop-GFP + CAGGS mCherry (Figure 2D) resulted in broad expression of mCherry and specific GFP labelling of cells located at the Atoh $1^{+}$rhombic lip or more ventrally located stripes of Ptf1a progenitors, respectively. The expression of Atoh1 and Ptf1a revealed by in situ hybridisation (Figure 2B) was faithfully recapitulated by the enhancer driven GFP expression from the reporter constructs (Figure 2C,D). Second, we used enhancer elements from four transcription factors whose expression maps onto segmental boundaries of the early, rhombomeric hindbrain: Egr2 (Krox20), Hoxb1 Hoxa3 and Hoxd4. The expression pattern of the segmental markers was recapitulated by the reporter constructs employed. An Egr2 enhancer element directed GFP expression to r3 and r5 (Chomette et al., 2006); a Hoxb1 enhancer element directed GFP expression to r4 (Ferretti et al., 2005); a Hox3 enhancer element directed GFP expression to r5 and r6 (Manzanares et al., 2001) and finally a Hoxd4 enhancer element directed GFP expression caudal to the $r 6 / r 7$ boundary (Morrison et al., 1997) (Figure 2E).

To achieve a comprehensive anatomical identification of hindbrain structures, electroporated embryos were incubated to embryonic day 10 (E10) and the distribution of cells within hindbrain nuclei assessed in coronal cryosections. All structures were identified based on the fluorescent signal from the electroporated constructs, nuclear counterstaining and in reference to Nissl stained sections of equivalent orientation and stage (Figure $\mathbf{3 A}$ ). Fluorescent label was contrasted to Nissl derived templates (Figure 3B) to identify nuclear boundaries on the basis of cytoarchitecture and in reference to avian brain anatomy atlas (Kuenzel and Masson, 1988).

\section{Avian hindbrain first order auditory nuclei are defined by axially distinct pools of Atoh1 and Ptf1a precursors}

In birds, primary auditory afferents synapse at the Nucleus Magnocellularis (NM) and Nucleus Angularis (NA) (Ryugo and Parks, 2003). NM neurons, characterised by their bifurcating ipsilateral and contralateral projections, are labelled by electroporation with Atoh1-Cre + Stop-GFP (Atoh1::GFP) (Figure 4A). Ipsilateral axonal projections from NM neurons were observed surrounding the lateral border of the NM on their way towards the Nucleus Lateralis (NL) and 
bioRxiv preprint doi: https://doi.org/10.1101/372243; this version posted July 18, 2018. The copyright holder for this preprint (which was not certified by peer review) is the author/funder, who has granted bioRxiv a license to display the preprint in perpetuity. It is made available under aCC-BY-NC-ND 4.0 International license.

terminating on its dorsal region (Figure 4B). At the contralateral (non-electroporated) side, NM axons were observed contacting the ventral side of NL neurons (Figure 4C). At its caudal end, the border between NM and the Descending Vestibular Nucleus (VeD) is difficult to distinguish (Figure 4D). No Ptf1a labelled neurons were found within the NM upon electroporation with Ptf1a-Cre + PBase +Pb-Stop-GFP (Ptf1a::GFP - Figure 4E).

Electroporation with Egr2-Cre + PBase + Pb-Stop-GFP (Egr2::GFP - Figure 4F) and Hoxa3-Cre + PBase +Pb-Stop-GFP (Hoxa3::GFP - Figure 4G) resulted in scattered labelling of NM cells, arising from r5 and r6. Electroporation with Hoxb1-Cre + PBase + Pb-Stop-GFP (Hoxb1::GFP) labelled cells in the NM area, but not Atoh1 ${ }^{+}$NM neurons, labelled with Atoh1-Gal4 + UAS-tdT (Atoh1::tdT) (Figure $\mathbf{4 H}$ ). Finally, electroporation with Hoxd4-Cre + PBase + Pb-Stop-GFP (Hoxd4::GFP) resulted in abundant labelling of NM cells (Figure 4I). This caudal rhombic lip origin of NM cells was confirmed via a transectional labelling strategy, wherein electroporation with Hoxd4-Cre + Atoh1-FLPo + Flox/FRTStop-GFP + CAGGS-mCheery resulted in GFP expression after double Cre/FLp recombination driven by Hoxd4 and Atoh1 enhancer elements (Figure $4 \mathrm{~J}$ ). The rhombic lip and axial origin of NM cells is summarised in figure $\mathbf{4 K}$.

The Nucleus Angularis (NA) is composed of at least 4 morphologically and electrophysiologically distinct neuronal types: radial, vertical, stubby and planar cells (Soares and Carr, 2001; Soares et al., 2002). Electroporation with Atoh1::GFP resulted in extensive labelling of NA neurons (Figure 4L), that showed morphologies indicative of radial, vertical and planar cells (Figure $\mathbf{4 M}$ ). Electroporation with Ptf1a::GFP resulted in more scattered labelling of the NA. Ptf1a ${ }^{+}$NA cells had the distinctive spiny morphology of stubby cells (Figure 4N). Planar, radial and vertical cells (likely Atoh1), but not stubby (likely Ptf1a) cells, were labelled following electroporation with Egr2::GFP (Figure 40). By contrast, all four cell types were labelled by Hoxb1::GFP electroporations (Figure 4P). This suggests that, while Atoh $1^{+}$NA cells derived from $r 3, r 4$ and $r 5$ (and this may include vertical, planar and radial morphological types), only r4 Ptf1a+ progenitors gave rise to NA stubby cells (Figure 4K).

In summary, we observed that the Atoh1 and Ptf1a lineages accounted for all the described cell types in the avian first order hindbrain auditory nuclei. While the axial origin of NA cells was located towards the more rostral rhombomeres, NM cells were observed arising from the caudal rhombic lip (Figure 4K).

The Atho1 positive rhombic lip is a main source of avian hindbrain second order auditory neurons

In chick, the Nucleus Laminaris (NL) and Superior Olivary Nucleus (SON) comprise the hindbrain second order neuronal populations. They receive input from the NA and NM and are involved in the processing of monaural and binaural auditory cues (Carr and Soares, 2002). The NL sits ventral to the 
bioRxiv preprint doi: https://doi.org/10.1101/372243; this version posted July 18, 2018. The copyright holder for this preprint (which was not certified by peer review) is the author/funder, who has granted bioRxiv a license to display the preprint in perpetuity. It is made available under aCC-BY-NC-ND 4.0 International license.

NM and is composed of neurons aligned on a plane along the mediolateral axis. Electroporation with Atoh1::GFP resulted in strong labelling of NL neurons (Figure 5A) that reveals their characteristic bipolar dendritic morphology (Figure 5A - inset), with segregated dorsal and ventral dendrites.

Electroporation with Egr2::GFP results in two distinct bands of GFP expression corresponding to r3 and $\mathrm{r} 5$. Cells of the NL were observed in the caudal band of GFP expression (Figure 5B) suggesting they originated from progenitors in $r 5$, but not $r 3$. NL cells were also labelled by electroporation with Hoxb1::GFP (Figure 5C) and Hoxa3::GFP (Figure 5D), indicating NL neurons derived from r4-r6 progenitors as summarised in figure $\mathbf{5 E}$. No Ptf1a labelled neurons were found within the NL.

The SON is located in the ventrolateral hindbrain (Figure $\mathbf{3}$ and $\mathbf{5 F}$ ). Electroporation with Atoh1::GFP resulted in extensive labelling of SON neurons (Figure 5F). By contrast, electroporation with Ptf1a::GFP only occasionally labelled one or two small cells in the nucleus (Figure 5G - arrowhead).

Electroporation with Egr2::GFP resulted in extensive labelling of SON neurons (Figure 5H). Colabelling with Egr2::GFP and Atoh1::tdT showed both Egr2 ${ }^{+} /$Atoh1 $^{-}$and Egr2 ${ }^{-} /$Atoh1 $^{+}$cells, as well as many double labelled $\mathrm{Egr2}^{+} / \mathrm{Atoh}^{+}$cells (Figure 5I). This suggested that, within $\mathrm{r} 5$, Atoh1 ${ }^{+}$ progenitors are not the exclusive source of SON neurons. In addition, electroporation with Hoxb1::GFP (Figure 5J) and Hoxa3::GFP (Figure 5K) labelled scattered cells in the SON, suggesting a small contribution from both $\mathrm{r} 4$ and $\mathrm{r} 6$ to the predominantly $\mathrm{r} 5$ derived SON (Figure 5E).

In summary, both second order auditory nuclei originated from mid-hindbrain progenitors, namely, $r 4$ to $r 6$. The NL is composed of only one cell type from the Atoh $1^{+}$rhombic lip. In contrast, the SON is more heterogeneous and composed of cells arising from both Atoh $1^{+}$and Atoh1- progenitors. While the latter may include cells of Ptf1a origin, these most likely originate from other progenitor populations.

\section{Ptfi1a and Atoh1 lineages contribute distinct neuronal populations to hindbrain vestibular nuclei}

The vestibular nuclear complex extends rostro-caudally along the entire dorsal hindbrain. Six vestibular nuclei are commonly recognised in birds: superior, Deiters dorsal, Deiters ventral, tangential, medial and descending (Wold, 1976). Vestibular neuronal groups are also defined in terms of a repertoire of projection patterns (such as vestibulo-ocular, vestibulo-spinal and vestibulocerebellar) that are common to all vertebrates (Pasqualetti et al., 2007; Straka and Baker, 2013; Straka et al., 2002). However, neurons projecting to different targets are usually intermingled within a given nucleus or span more than one nucleus (Buttner-Ennever, 1992; Daz and Puelles, 2003; Di Bonito et al., 2015; Petursdottir, 1990). Accordingly, the different vestibular nuclei are comprised of highly heterogeneous neuronal populations. With the exception of the tangential nucleus, all the vestibular nuclei in birds have a homologous counterpart in vertebrates (Straka and Baker, 2013). 
bioRxiv preprint doi: https://doi.org/10.1101/372243; this version posted July 18, 2018. The copyright holder for this preprint (which was not certified by peer review) is the author/funder, who has granted bioRxiv a license to display the preprint in perpetuity. It is made available under aCC-BY-NC-ND 4.0 International license.

The Superior Vestibular Nucleus (VeS) is the most rostral of the vestibular nuclei and has a heterogeneous complement of cells (Wold, 1976). Electroporation with Atoh1::GFP resulted in scattered labelling of cells in the VeS, with diverse morphology (Figure 6A). Electroporation with Egr2::GFP also labelled diverse VeS neurons (Figure 6B) that are most likely derived exclusively from $r 3$, as r5-derived territory lies considerably caudal to the nucleus, with no labelled cells found in the intervening, presumably $\mathrm{r} 4$ derived, territory. Upon electroporation with Hoxb1::GFP, we observed a small number of isolated Hoxb $1^{+}$cells in the VeS (Figure 6C - arrowheads). The rhombic lip and axial origin of VeS cells is summarised in figure 6D.

The morphologically distinct Nucleus Deiters Ventralis (Dv) and Nucleus Deiters Dorsalis (Dd) are characterised by the presence of giant cells, amidst a collection of smaller cells of diverse morphologies (Wold, 1976). Electroporation with Atoh1::GFP resulted in abundant labelling of cells in the Dd and more scattered labelling in the Dv (Figure 6E). Giant, oval cells of the Dd were never observed labelled with Atoh1::GFP, while a single giant multipolar Dv cell was labelled with Atoh1::GFP in only one occasion, in contrast with more frequent labelling of smaller cells (Figure 6F). Electroporation with Ptf1a::GFP also resulted in abundant labelling of cells in the Dd and Dv (Figure 6G), including numerous small cells (Figure 6H - top panel, arrowheads), that showed a different morphology to the characteristic Dd giant oval cells (Figure 6H - top panel, asterisks), and medium/small size cells in the Dv (Figure $6 \mathbf{H}$ - bottom panel, arrowheads).

Axial markers allocated the origin of the Deiters nuclei to the mid-hindbrain rhombomeres. Electroporation with Egr2::GFP resulted in scattered labelling of Dd (Figure $6 \mathbf{I}$ - left panel) and Dv (Figure 6I - right panel) cells, none of which showed morphological features of giant cells. Electroporation with Hoxb1:: GFP also resulted in labelling of cells in the Dd and Dv, showing a wider range of morphologies, including giant oval cells in the Dd (Figure 6J - left panel) and giant multipolar cells in the Dv (Figure 6 J - right panel). In summary, both Atoh1 and Ptf1a progenitors from r3-r5 gave rise to cells in the dorsal and ventral Deiter's nuclei (Figure 6D). The distinct giant cells appeared to originate from $r 4$ progenitors that may not correspond to either Atoh $1^{+}$or Ptf $1 a^{+}$ lineages.

The Nucleus Tangentialis ( $\mathrm{Ta}$ ) is composed of elongated cells that are located tangential to the incoming VIIIth nerve fibres (Wold, 1976). Electroporation with Atoh1::GFP did not label cells in the Ta (Figure 6K), while Ptf1a::GFP labelling showed only scattered small cells in the Ta territory, none of which corresponded to the characteristic elongated Ta cells (Figure 6L). The latter were labelled by electroporation with Egr2::GFP (Figure 6M), Hoxb1::GFP (Figure 6N) and Hoxa3::GFP (Figure 60), indicating they may derive from Atoh1-/Ptf1a-negative precursors from r4-r6 (Figure 6D). 
bioRxiv preprint doi: https://doi.org/10.1101/372243; this version posted July 18, 2018. The copyright holder for this preprint (which was not certified by peer review) is the author/funder, who has granted bioRxiv a license to display the preprint in perpetuity. It is made available under aCC-BY-NC-ND 4.0 International license.

The Medial Vestibular Nucleus (VeM) is located beneath the ventricular surface and closely associated with the auditory NM. Contralaterally projecting NM axons divide the VeM into dorsomedial and ventrolateral parts (Figure 7A). Electroporations with Atoh1::GFP showed scattered labelling of VeM cells (Figure 7A and inset), including neurons embedded within the NM fibre tract (Figure 7A - arrow). Electroporation with Ptf1a::GFP revealed abundant Ptf1a derived neurons in both parts of the nucleus (Figure 7B). The VeM has the longest rostrocaudal extent of all the vestibular nuclei (Wold, 1976). Egr2::GFP electroporations labelled numerous cells in the rostral VeM (Figure 7C- left panel), and only scattered cells more caudally, at the level adjacent to the rostral NM (Figure 7C - right panel, arrowheads). VeM cells at this axial level were also labelled via electroporation with Hoxb1 (Figure 7D) and Hoxa3 (Figure 7E) reporter constructs, whilst the middle and caudal VeM was mainly labelled by Hoxd4::GFP electroporations (Figure 7F). In summary, VeM cells were observed originating from Atoh $1^{+}$and $\mathrm{Ptf} \mathrm{a}^{+}$progenitors spanning from $\mathrm{r} 3$ to axial levels caudal to $r 7$ (Figure 7G).

The Descending Vestibular Nucleus (VeD) extends rostrocaudally from the level of the VIIIth nerve root to the caudal end of the hindbrain (Wold, 1976). Electroporation with Atoh1::GFP resulted in profuse labelling of neurons in the caudal VeD (Figure $\mathbf{7 H}$ ) and more scattered cell labelling in the rostral portion of the nucleus, through which NL axons course into the ventral hindbrain and SON axons reach the NL (Lachica et al., 1994; Takahashi and Konishi, 1988) (Figure 7I). Electroporations with Ptf1a::GFP resulted in labelling of small cells throughout the VeD (Figure 7J). The rostral portion of the VeD showed cells labelled via electroporation with Egr2::GFP (Figure 7K) and Hoxa3::GFP (Figure 7L). In turn, the middle and caudal portions of the VeD were labelled by electroporation with Hoxd4::GFP (Figure 7M). Finally, electroporations with Hoxb1::GFP labelled scattered cells in the rostral VeD (Figure $\mathbf{7 N}$ ), which may have migrated caudally from $r 4$. In summary, our characterisation of the VeD showed cells arising from both Atoh1 and Ptf1a progenitors that span r4 to levels caudal to $\mathbf{7}$ (Figure 7G).

Figure 8 summarises the cells identified as arising from Atoh $1^{+}$or Ptf1 $\mathrm{a}^{+}$progenitors in the chick hindbrain auditory and vestibular nuclei, as well as those labelled by the different rhombomeric markers. Our enhancer-based mapping data is portrayed together with chick/quail chimera (Cambronero and Puelles, 2000; Marin and Puelles, 1995) and Dil injection (Cramer et al., 2000) mapping and in comparison with the fate-mapping of the corresponding mouse hindbrain nuclei (Altieri et al., 2015; Chen et al., 2012; Di Bonito et al., 2015; Di Bonito et al., 2013; Di Bonito and Studer, 2017; Di Bonito et al., 2017; Farago et al., 2006; Fujiyama et al., 2009; Machold and Fishell, 2005; Maricich et al., 2009; Marrs et al., 2013; Marrs and Spirou, 2012; Meredith et al., 2009; 
bioRxiv preprint doi: https://doi.org/10.1101/372243; this version posted July 18, 2018. The copyright holder for this preprint (which was

not certified by peer review) is the author/funder, who has granted bioRxiv a license to display the preprint in perpetuity. It is made available under aCC-BY-NC-ND 4.0 International license.

Pasqualetti et al., 2007; Rose et al., 2009; Tomas-Roca et al., 2016; Wang et al., 2005; Yamada et al., 2007). 
bioRxiv preprint doi: https://doi.org/10.1101/372243; this version posted July 18, 2018. The copyright holder for this preprint (which was

\section{Discussion}

In this study, we have mapped the rhombic lip/Atoh1, ventricular zone/Ptf1a and axial origin of chick hindbrain vestibular and auditory nuclei. This shows, for the first time, the origins of both systems by rhombomeric identity and specific dorsoventral lineage. Our data give a solid framework by which to assess divergence and convergence within hindbrain functional circuits in birds and mammals. We evaluate the contribution of changes in hindbrain development to the evolution of neuronal circuits, within the context of disparaging evolutionary histories of the different amniote vestibular and auditory structures.

\section{Anatomical, morphological and developmental features indicate a high degree of conservation of}

\section{hindbrain vestibular nuclei across vertebrates}

Vestibular peripheral organs, hindbrain vestibular nuclei and their connectivity patterns are highly conserved across vertebrates and clear evolutionary relationships can be established (Straka and Baker, 2013). The axial developmental origin and location of vestibular neurons projecting to oculomotor, spinal cord, cerebellar and commissural targets are also conserved (Branoner et al., 2016; Chagnaud et al., 2017; Malinvaud et al., 2010; Straka and Baker, 2013; Straka et al., 2014), however, a comparative analysis of the dorsoventral lineage of hindbrain vestibular neurons has been lacking. Here, we show that in chick, cells derived from rhombic lip Atoh $1^{+}$progenitors are present in the Superior, Deiters, Medial and Descending vestibular nuclei, while we observed no contribution from this lineage to the avian exclusive Tangential nucleus (Figures $\mathbf{5}$ and $\mathbf{6}$ ). Moreover, we have identified cells derived from Ptf $1 \mathrm{a}^{+}$progenitors in the Deiters, tangential, medial and descending vestibular nuclei (Figures 5 and $\mathbf{6}$ ). These results are similar to fate maps in mouse showing that rhombic lip Atoh $1^{+}$progenitors contribute to the superior (Wang et al., 2005), lateral, medial and spinal vestibular nuclei (Rose et al., 2009), while Ptf1a ${ }^{+}$progenitors give rise to vestibular hindbrain neurons, possibly located in all four nuclei (Yamada et al., 2007). Of note, Atoh1 and Ptf1a cells do not account for the whole diversity of cell types, in either chick or mouse (Figure 8), and further mapping efforts are required to fully characterise the genetic lineages that give rise to the myriad of hindbrain vestibular neurons.

Our high resolution electroporation-based labelling allowed for a detailed characterisation of the axial origin of vestibular neuronal types (Figure 8). The Nucleus Deiters Ventralis (Dv) and Nucleus Deiters Dorsalis (Dd) of birds are homologous to the rostroventral and dorsocaudal part of the mammalian lateral vestibular nucleus, respectively (Passetto et al., 2008), which is mainly derived from r4 progenitors (Chen et al., 2012; Di Bonito et al., 2015), with additional contribution from r3 and r5 (Pasqualetti et al., 2007). Here, we observed a similar axial origin for both the Dv and Dd, with 
bioRxiv preprint doi: https://doi.org/10.1101/372243; this version posted July 18, 2018. The copyright holder for this preprint (which was not certified by peer review) is the author/funder, who has granted bioRxiv a license to display the preprint in perpetuity. It is made available under aCC-BY-NC-ND 4.0 International license.

progenitors allocated to $\mathrm{r} 3, \mathrm{r} 4$ and $\mathrm{r} 5$ (Figures $6 \mathrm{I}, \mathrm{J}$ and 9 ). Moreover, Dv and Dd giant cells derived exclusively from $\mathrm{Hoxb1}^{+}(\mathrm{r} 4)$ progenitors. These may constitute a homologous cell type to the $\mathrm{r} 4$ derived large stellate cells of the murine lateral (and medial) vestibulospinal tract (Di Bonito et al., 2015; Di Bonito et al., 2017). Finally, we observed a minor group of small r4 derived cells that integrate into the VeS and VeM, invading $\mathrm{r} 3$ and $\mathrm{r} 5$ derived territories, respectively (Figures 6 B and 7 D). A similar group of cells has been described in mouse (Di Bonito et al., 2017) and shown to also belong to the highly conserved vestibulospinal tract. Taken together, these observations support a homologous axial and dorso-ventral origin for spinal cord projecting neurons from both species and highlight the high degree of conservation in the detailed organisation of the ancestral vestibulospinal tract (Straka and Baker, 2013).

\section{Avian first order hindbrain auditory neurons may be related to vertebrate ancestral vestibuloacoustic neurons}

Our electroporation-based fate mapping showed neurons in the chick first order NA arising from either Atoh1 or Ptf1a progenitors (Figures $\mathbf{4} \mathbf{K}-\mathbf{N}$ and $\mathbf{8}$ ), thus sharing a developmental origin with the neurons of the mammalian ventral cochlear nucleus (VCN) (Figure 8 and (Fujiyama et al., 2009)). Moreover, both NA and VCN neurons share a common axial origin from rostral rhombomeres (Figures. 4 K,O-P and 8 and (Cramer et al., 2000; Di Bonito et al., 2013; Di Bonito et al., 2017; Farago et al., 2006; Marin and Puelles, 1995)). This developmental conservation suggests that anterior neurons of the ascending auditory pathway of amniotes may be homologous. Furthermore, first order NA neurons in birds/reptiles were proposed to be related to dorsal neurons of the fish anterior octaval nucleus (Walton et al., 2017). These anteriorly derived neurons may thus comprise a developmentally conserved brainstem first order relay point for auditory (particle vibration) information.

The first order NM occupies a major portion of the diapsid caudal/dorsal hindbrain. NM neurons are derived from progenitors in the alar plate (Tan and Le Douarin, 1991) of the caudal hindbrain (Cambronero and Puelles, 2000; Cramer et al., 2000; Marin and Puelles, 1995). Our enhancer-based mapping confirmed this and further showed that NM neurons originate exclusively from rhombic lip $\left(\right.$ Atoh $1^{+}$) progenitors located caudal to r5 (Figures 4 A-K and 8). In zebrafish, Atoh1 is required for the development of a subpopulation of $\mathrm{zn}^{-5^{+}}$and $\mathrm{Lh} \times 2 / \mathrm{9}^{+}$cells that may correspond to contralaterally projecting octaval neurons (Sassa et al., 2007) and preliminary mapping data shows Atoh1 labelling of neurons on the caudal octaval nucleus (Wullimann et al., 2011). Moreover, it has been proposed that NM neurons may derive from an ancestral population equivalent to extant neurons of the dorsal descending octaval nucleus of fish (Carr and Christensen-Dalsgaard, 2016; Walton et al., 2017), which are part of a binaural circuit that sharpens directional information from 
bioRxiv preprint doi: https://doi.org/10.1101/372243; this version posted July 18, 2018. The copyright holder for this preprint (which was not certified by peer review) is the author/funder, who has granted bioRxiv a license to display the preprint in perpetuity. It is made available under aCC-BY-NC-ND 4.0 International license.

the saccule (Edds-Walton, 2016). Overall, this suggests that extant caudal octaval (vestibuloacoustic) neurons in chick that belong to the auditory NM and the vestibular DeV may be ancestrally related. Morphologically, a close association is present between the two nuclei at the level of the caudal end of the NM (Figure $4 \mathrm{D}$ ) with some VeD cells extending contralateral projections that join the NM dorsal (cochlear) commissure (Figure 4 D - arrows). Finally, our observation that NM and VeD neurons share a developmental origin in the caudal rhombic lip, with a significant number of VeD neurons labelled via Atoh1 electroporations (Figure 7 H) supports a common evolutionary origin for NM and rhombic lip derived VeD neurons.

\section{The analogous avian and mammalian ITD circuits have separate evolutionary and developmental} origins.

Both mammals and diapsids have brainstem interaural time difference (ITD) sound localisation circuits, with overall similar organisation. However, functional and morphological studies have shown that the similarities are superficial and indicate that the ITD circuits are an example of convergent evolution (Carr and Christensen-Dalsgaard, 2016; Carr and Soares, 2002; Grothe et al., 2004; Grothe and Pecka, 2014; Grothe et al., 2010). Our developmental analysis supports this hypothesis by 1) confirming differences in origin of first order nuclei, 2) revealing divergence in the origins of second order coincidence detectors and 3) showing a multifaceted developmental and evolutionary history for the neurons that provide inhibitory modulation to the ITD circuit.

NM neurons are the bilaterally projecting neurons of the diapsid ITD circuit and they are broadly considered the functional counterpart of the first order spherical bushy cells (SBCs) of the mammalian VCN (Carr and Soares, 2002). Both neuronal types have bifurcating ipsilateral and contralateral projections to coincidence detection nuclei. However, SBCs and NM neurons follow different projection trajectories and, while contralateral NM axons are arranged in a delay line that spans the mediolateral extent of the NL (Figure 1 D,E) in accordance with the Jeffres model (Ashida and Carr, 2011), no such arrangement is present for SBCs axons reaching the contralateral medial superior olive (MSO) (Karino et al., 2011). Also, while NM neurons contact exclusively the NL within the auditory brainstem (Carr and Soares, 2002; Takahashi and Konishi, 1988; Wild et al., 2010), SBCs send collateral projections to the lateral superior olive (LSO) and nucleus of the trapezoid body (NTB), in addition to the MSO (Cant and Benson, 2003; Smith et al., 1993), indicating that they participate in multiple instances of auditory information processing. Finally, while both NM neurons and SBCs arise from Atoh $1^{+}$rhombic lip progenitors (Figures $\mathbf{4}$ A-E,K and $\mathbf{8}$ and (Di Bonito and Studer, 2017; Fujiyama et al., 2009)), their axial origin differs. NM cells originate from the caudal hindbrain, posterior to rhombomere 5 (Figures 4 F-K and $\mathbf{8}$ and (Cambronero and Puelles, 2000; Cramer et al., 2000; Marin and Puelles, 1995)), while SBCs originate from rostral rhombomeres (Di Bonito and 
bioRxiv preprint doi: https://doi.org/10.1101/372243; this version posted July 18, 2018. The copyright holder for this preprint (which was not certified by peer review) is the author/funder, who has granted bioRxiv a license to display the preprint in perpetuity. It is made available under aCC-BY-NC-ND 4.0 International license.

Studer, 2017; Farago et al., 2006). This is in agreement with the proposition that NM cells derive from ancestral vestibuloacoustic cells of the caudal octaval column (previous section and (Carr and Christensen-Dalsgaard, 2016; Walton et al., 2017)), while SBCs may be an elaboration of components of an interaural level difference (ILD) circuit, which, in mammals, is proposed to predate the ITD circuit (Grothe and Pecka, 2014). The comparison of the developmental origin of NM neurons and SBCs thus supports an independent evolutionary origin for these functionally analogous cell types.

Second order coincidence detection nuclei of mammals and birds (MSO and NL, respectively) show remarkably similar morphologies, with a linear arrangement of bipolar neurons that receive segregated binaural input. (Figure $1 \mathbf{D , E}$ and (Carr and Soares, 2002)). However, the NL and MSO differ in their location within the brainstem (Figure 1 C,D and (Grothe et al., 2004)), employ differing neural coding strategies (Grothe and Pecka, 2014; Grothe et al., 2010) and most likely have separate evolutionary origins (Carr and Christensen-Dalsgaard, 2016; Grothe et al., 2004; Grothe and Pecka, 2014; Walton et al., 2017). In mammals, the MSO is proposed to be an elaboration of the LSO which computes ILDs (Grothe and Pecka, 2014). The MSO contains coincidence detection glutamatergic bipolar neurons that derive from Atoh $1^{+}$rhombic lip progenitors in $\mathrm{r} 5$, in addition to GABAergic neurons of unknown origin (Altieri et al., 2015; Di Bonito and Studer, 2017; Maricich et al., 2009; Marrs et al., 2013; Marrs and Spirou, 2012; Rose et al., 2009). By contrast, we show here that the avian NL, composed of a single type of bitufted neurons, is exclusively derived from Atoh $1^{+}$ progenitors that overlap with the rostral end of the rhombic lip derived $N M$ at $r 5$ and $r 6$, with an additional contribution from r4 (Figures 5 A-E). The development of NL neurons progresses within the auditory anlage together with that of NM neurons (Book and Morest, 1990; Hendricks et al., 2006). On the whole, this supports a common developmental and evolutionary origin for NM and NL neurons, deriving from the ancestral descending octaval nucleus (Grothe et al., 2004), and entirely distinct from the origin of first order SBCs and bipolar MSO neurons of the mammalian ITD circuit (Grothe and Pecka, 2014).

Finally, inhibitory modulation of coincidence detection neurons is fundamentally different between amniote ITD circuits. In mammals, inhibitory input to MSO neurons is glycinergic, bilateral, phasedlocked and provided by LNTB and MNTB neurons (Grothe, 2003; Grothe and Pecka, 2014; Grothe et al., 2010; Myoga et al., 2014). In birds, inhibition of NL neurons is GABAergic, unilateral, tonic and provided by the SON (Burger et al., 2011; Grothe, 2003; Grothe and Pecka, 2014; Grothe et al., 2010). No individual mammalian nucleus has been identified as equivalent to the diapsid SON (Burger et al., 2005; Burger et al., 2011; Grothe et al., 2004; Grothe et al., 2010; Tabor et al., 2012; Wild et al., 2010). Neurons in the SON originate from both the alar and basal plates (Tan and Le Douarin, 1991) in rhombomeres 4 and 5 (Figures 5 E-K and 8 - (Cambronero and Puelles, 2000; 
bioRxiv preprint doi: https://doi.org/10.1101/372243; this version posted July 18,2018 . The copyright holder for this preprint (which was not certified by peer review) is the author/funder, who has granted bioRxiv a license to display the preprint in perpetuity. It is made available under aCC-BY-NC-ND 4.0 International license.

Cramer et al., 2000; Marin and Puelles, 1995), and possibly rhombomere 6, and include a large complement of Atoh $1^{+}$rhombic lip derived neurons that, most likely, do not provide the inhibitory modulation to the ITD circuit. Although we could not identify the origin of the GABAergic neurons that comprise about $70 \%$ of the SON cells (Lachica et al., 1994) and provide descending input to the NL, NM and NA (Burger et al., 2005; Wild et al., 2010), it is likely that these are specifically born in r5 (Figures 5 and 8) and of basal origin (Tan and Le Douarin, 1991). Interestingly, this raises the possibility of a common developmental origin with neurons of the mammalian NTB that also originate in rhombomere 5, from basal plate progenitors belonging to the En-1 lineage (Altieri et al., 2015; Di Bonito and Studer, 2017; Maricich et al., 2009; Marrs et al., 2013). Moreover, the mixed developmental origin of the SON resembles that of the mammalian olivary complex as a whole (to which the LSO, MSO and NTB belong) and that is also derived from both basal and alar (including rhombic lip) progenitors. This suggests the possibility of an alar/basal plate derived ancestral amniote second order vestibuloacoustic nucleus located in the ventral hindbrain and composed of multiple neuronal types that would have integrated ascending pathways and provided descending modulatory input to other brainstem vestibuloacoustic nuclei. The extant diapsid SON and mammalian superior olivary complex would thus be independent elaborations of this ancestral second order ventral nucleus.

In summary, the comparative development of ITD circuit components shows a mixture of ancestral and derived features. Subcircuits belonging to the ascending pathways seem to be conserved (e.g. NA and VCN neurons). However, while the mammalian bilateral input (SBC) and coincidence detection neurons (MSO) likely emerged as an elaboration of the ancestral mammalian ILD circuit (Grothe and Pecka, 2014), our developmental analysis supports the hypothesis that the avian NM/NL subcircuit may have emerged as an elaboration of a more ancient vertebrate vestibular network (Carr and Christensen-Dalsgaard, 2016; Walton et al., 2017). 
bioRxiv preprint doi: https://doi.org/10.1101/372243; this version posted July 18, 2018. The copyright holder for this preprint (which was

\section{Methods}

\section{Cloning of enhancer elements and plasmids}

An Atoh1 enhancer (Helms et al., 2000) was used to direct Cre recombinase expression to cells derived from the rhombic lip (Kohl et al., 2012). The same element was also subcloned upstream the Gal4 coding sequence (kind gift from Martin Meyer, King's College London) or the FLPo recombinase coding sequence (Hadas et al., 2014) to allow for the intersectional labelling of cells. A Ptf1a short enhancer element (Meredith et al., 2009) was subcloned upstream the Cre recombinase cloning sequence and used to identify a population of cells originating from the ventricular zone. All subclonings were performed using the Gibson Assembly kit (New England Biolabs).

For the labelling of cells originating at different antero-posterior levels along the hindbrain, a set of rhomobomere specific enhancer elements were employed. An Egr2 (Krox20) enhancer element (Chomette et al., 2006) was used to direct Cre recombinase expression to $r 3$ and $r 5$. An enhancer element from Hoxb1 (Ferretti et al., 2005) was used to direct Cre expression to r4. A Hoxa3 enhancer element (Manzanares et al., 2001) was used to direct Cre expression to r5/r6. Finally, an enhancer element from Hoxd4 (Morrison et al., 1997) was used to direct Cre expression to $>r 7$. The enhancer elements were PCR amplified from mouse genomic DNA, and subcloned upstream of the Cre recombinase coding sequence using the Gibson Assembly kit (New England Biolabs). Primers used for each step are listed in Table 1.

The different enhancer driven expression plasmids were co-electroporated with their corresponding reporter plasmids, driving Cre, FLPo or Gal4 dependent expression of fluorescent proteins. The following reporter plasmids were employed: pCAGG-LoxP-pA-LoxP-EGFP, pCAGG-FRT-pA-FRT-LoxPpA-LoxP-EGFP and UAS-tdT. On experiments using Ptf1a, Egr2, Hoxb1, hoxa3 and Hoxd4 enhancers, the PiggyBac DNA-transposition system was used to achieve integration of the reporter gene into the chick genome and therefore persistent labelling of the targeted cells (Hadas et al., 2014). The reporter construct in this case consisted of a Cre-dependent GFP cloned between the two PB arms and was co-electroporated with an enhancer-Cre plasmid and a plasmid encoding for the Pbase transposase (Sanger Institute). As a control for the successfully targeted area, a CAGG-mCherry plasmid was co-electroporated in most experiments. All plasmids and sequences are available upon request.

\section{In ovo electroporations}

Fertilised hen's eggs were incubated at $38^{\circ} \mathrm{C}$. Electroporations were performed at stages $\mathrm{HH} 12-15$ (Hamburger, 1951). Briefly, eggs were windowed using sharp surgical scissors. The $4^{\text {th }}$ ventricle was injected with $100-200 \mathrm{nl}$ of the corresponding plasmids DNA at equimolar concentrations and to a 
bioRxiv preprint doi: https://doi.org/10.1101/372243; this version posted July 18, 2018. The copyright holder for this preprint (which was not certified by peer review) is the author/funder, who has granted bioRxiv a license to display the preprint in perpetuity. It is made available under aCC-BY-NC-ND 4.0 International license.

final concentration of $1-3 \mu \mathrm{g} / \mu \mathrm{l}$. Three $20 \mathrm{~ms} / 10 \mathrm{~V}$ square waveform electrical pulses were passed between electrodes placed on either side of the hindbrain. Tyrode's solution supplemented with penicillin/streptomycin (Sigma) was added before the eggs were resealed and incubated for a further 1 or 8 days at $38^{\circ} \mathrm{C}$. A minimum of three batches of independent electroporations were performed for each of the plasmid combinations employed. A minimum of two embryos were fully processed (dissected, sectioned, stained, imaged and analysed) for each of the electroporations performed.

\section{Tissue processing, immunostaining and imaging}

Embryos were collected after 3 to 10 days of incubation, the hindbrain was dissected out and fixed in $4 \%$ paraformaldehyde (in phosphate-buffered saline). For in situ hybridisation E4 dissected hindbrain tissue was stained as previously described (Myat et al., 1996) with digoxygenin or fluorescein-labelled riboprobes (Roche) for: Atoh1 (Wilson and Wingate, 2006) and Ptf1a (ChEST102804, (Green et al., 2014)), flatmounted on $80 \%$ glycerol and imaged from the dorsal side. . A different set of E10 dissected hindbrains were sectioned at $10 \mathrm{um}$ and stained with cresyl violet.

Electroporated E3/E6 wholemount hindbrains were flatmounted on $80 \%$ glycerol and imaged from the dorsal side. Electroporated E10 hindbrains were cryoprotected using a sucrose gradient, embedded in OCT (VWR) and frozen on liquid nitrogen. Floating coronal cryosections of $80 \mu \mathrm{m}$ thickness were washed three times in PBS. All sections were counterstained with NucRed (Molecular Probes). Sections labelled for Egr2, Hoxb1, Hoxa3 or Hoxd4 were immunostained for GFP. Briefly, floating cryosections were washed three times $30 \mathrm{~min}$ in PBS/1 \% TritonX-100 (PBSTx) before being washed in a blocking solution of $10 \%$ goat serum in PBSTx twice for one hour at room temperature. Anti-GFP antibody (rabbit IgG - 1:500, Invitrogen) was diluted in blocking solution and the sections were incubated at $4^{\circ} \mathrm{C}$ for 3 days. Samples were then rinsed in blocking solution and washed three times for one hour in blocking solution before adding an Alexa 488-conjugated goat anti-rabbit IgG, at 1:500 (Molecular Probes) diluted in blocking solution and incubating at $4^{\circ} \mathrm{C}$ for a further 2 days. Sections were then washed three times in PBS and nuclei were stained with NucRed (Molecular Probes). Sections were mounted on Prolong Diamond (Molecular probes).

Digital brightfield images were acquired on a stereo microscope (Leica MZFLIII). Laser scanning confocal microscopy images were acquired on an Olympus AX70 microscope. Image analysis and processing was performed in ImageJ and Photoshop.

All reports of positive labelling of cells belonging to a specific lineage, labelled by a given enhancer, at a given nucleus represent at least 3 independent observations in embryos obtained from 3 independent electroporations. 


\section{Author Contributions}

The study was conceived by ML and RJTW. The experimental work and data analysis was carried out by ML. The manuscript was written and revised by ML and RJTW.

\section{Acknowledgements}

We would like to thank Dr Martin Meyer and Dr Avihu Klar for kindly providing plasmid constructs and Prof Anthony Graham for invaluable comments on the manuscript. This work was supported by a Newton International Fellowship (Royal Society) to ML. 
bioRxiv preprint doi: https://doi.org/10.1101/372243; this version posted July 18, 2018. The copyright holder for this preprint (which was not certified by peer review) is the author/funder, who has granted bioRxiv a license to display the preprint in perpetuity. It is made available under aCC-BY-NC-ND 4.0 International license.

\section{References}

Altieri, S.C., Jalabi, W., Zhao, T., Romito-DiGiacomo, R.R., and Maricich, S.M. (2015). En1 directs superior olivary complex neuron positioning, survival, and expression of FoxP1. Developmental biology 408, 99-108.

Anthwal, N., Joshi, L., and Tucker, A.S. (2013). Evolution of the mammalian middle ear and jaw: adaptations and novel structures. Journal of anatomy 222, 147-160.

Ashida, G., and Carr, C.E. (2011). Sound localization: Jeffress and beyond. Curr Opin Neurobiol 21, 745-751.

Ben-Arie, N., Hassan, B.A., Bermingham, N.A., Malicki, D.M., Armstrong, D., Matzuk, M., Bellen, H.J., and Zoghbi, H.Y. (2000). Functional conservation of atonal and Math1 in the CNS and PNS.

Development 127, 1039-1048.

Book, K.J., and Morest, D.K. (1990). Migration of neuroblasts by perikaryal translocation: role of cellular elongation and axonal outgrowth in the acoustic nuclei of the chick embryo medulla. J Comp Neurol 297, 55-76.

Branoner, F., Chagnaud, B.P., and Straka, H. (2016). Ontogenetic Development of Vestibulo-Ocular Reflexes in Amphibians. Frontiers in neural circuits 10, 91.

Burger, R.M., Cramer, K.S., Pfeiffer, J.D., and Rubel, E.W. (2005). Avian superior olivary nucleus provides divergent inhibitory input to parallel auditory pathways. J Comp Neurol 481, 6-18.

Burger, R.M., Fukui, I., Ohmori, H., and Rubel, E.W. (2011). Inhibition in the balance: binaurally coupled inhibitory feedback in sound localization circuitry. Journal of neurophysiology 106, 4-14. Buttner-Ennever, J.A. (1992). Patterns of connectivity in the vestibular nuclei. Annals of the New York Academy of Sciences 656, 363-378.

Cambronero, F., and Puelles, L. (2000). Rostrocaudal nuclear relationships in the avian medulla oblongata: a fate map with quail chick chimeras. J Comp Neurol 427, 522-545.

Cant, N.B., and Benson, C.G. (2003). Parallel auditory pathways: projection patterns of the different neuronal populations in the dorsal and ventral cochlear nuclei. Brain research bulletin 60, 457-474.

Carr, C.E., and Christensen-Dalsgaard, J. (2016). Evolutionary trends in directional hearing. Curr Opin Neurobiol 40, 111-117.

Carr, C.E., and Soares, D. (2002). Evolutionary convergence and shared computational principles in the auditory system. Brain, behavior and evolution 59, 294-311.

Chagnaud, B.P., Engelmann, J., Fritzsch, B., Glover, J.C., and Straka, H. (2017). Sensing External and Self-Motion with Hair Cells: A Comparison of the Lateral Line and Vestibular Systems from a Developmental and Evolutionary Perspective. Brain, behavior and evolution 90, 98-116.

Chen, Y., Takano-Maruyama, M., Fritzsch, B., and Gaufo, G.O. (2012). Hoxb1 controls anteroposterior identity of vestibular projection neurons. PloS one 7, e34762.

Chomette, D., Frain, M., Cereghini, S., Charnay, P., and Ghislain, J. (2006). Krox20 hindbrain cisregulatory landscape: interplay between multiple long-range initiation and autoregulatory elements. Development 133, 1253-1262.

Clack, J.A. (2015). Evolutionary biology: The origin of terrestrial hearing. Nature 519, 168-169.

Cramer, K.S., Fraser, S.E., and Rubel, E.W. (2000). Embryonic origins of auditory brain-stem nuclei in the chick hindbrain. Developmental biology 224, 138-151.

Dallos, P. (2008). Cochlear amplification, outer hair cells and prestin. Curr Opin Neurobiol 18, 370376.

Daz, C., and Puelles, L. (2003). Plurisegmental vestibulocerebellar projections and other hindbrain cerebellar afferents in midterm chick embryos: biotinylated dextranamine experiments in vitro. Neuroscience 117, 71-82.

Di Bonito, M., Boulland, J.L., Krezel, W., Setti, E., Studer, M., and Glover, J.C. (2015). Loss of Projections, Functional Compensation, and Residual Deficits in the Mammalian Vestibulospinal System of Hoxb1-Deficient Mice. eNeuro 2. 
bioRxiv preprint doi: https://doi.org/10.1101/372243; this version posted July 18, 2018. The copyright holder for this preprint (which was not certified by peer review) is the author/funder, who has granted bioRxiv a license to display the preprint in perpetuity. It is made available under aCC-BY-NC-ND 4.0 International license.

Di Bonito, M., Narita, Y., Avallone, B., Sequino, L., Mancuso, M., Andolfi, G., Franze, A.M., Puelles, L., Rijli, F.M., and Studer, M. (2013). Assembly of the auditory circuitry by a Hox genetic network in the mouse brainstem. PLoS genetics 9, e1003249.

Di Bonito, M., and Studer, M. (2017). Cellular and Molecular Underpinnings of Neuronal Assembly in the Central Auditory System during Mouse Development. Frontiers in neural circuits 11, 18.

Di Bonito, M., Studer, M., and Puelles, L. (2017). Nuclear derivatives and axonal projections originating from rhombomere 4 in the mouse hindbrain. Brain structure \& function.

Duncan, J.S., and Fritzsch, B. (2012). Transforming the Vestibular System one Molecule at a Time: The Molecular and Developmental Basis of Vertebrate Auditory Evolution. In Sensing in Nature, C. Lopez-Larrea, ed. (Landes Bioscience and Springer Science+Business Media), pp. 173-186.

Edds-Walton, P.L. (2016). What the Toadfish Ear Tells the Toadfish Brain About Sound. Advances in experimental medicine and biology 877, 197-226.

Farago, A.F., Awatramani, R.B., and Dymecki, S.M. (2006). Assembly of the brainstem cochlear nuclear complex is revealed by intersectional and subtractive genetic fate maps. Neuron 50, 205218.

Ferretti, E., Cambronero, F., Tumpel, S., Longobardi, E., Wiedemann, L.M., Blasi, F., and Krumlauf, R. (2005). Hoxb1 enhancer and control of rhombomere 4 expression: complex interplay between PREP1-PBX1-HOXB1 binding sites. Molecular and cellular biology 25, 8541-8552.

Fritzsch, B., and Elliott, K.L. (2017). Gene, cell, and organ multiplication drives inner ear evolution. Developmental biology 431, 3-15.

Fritzsch, B., and Straka, H. (2014). Evolution of vertebrate mechanosensory hair cells and inner ears: toward identifying stimuli that select mutation driven altered morphologies. Journal of comparative physiology A, Neuroethology, sensory, neural, and behavioral physiology 200, 5-18.

Fujiyama, T., Yamada, M., Terao, M., Terashima, T., Hioki, H., Inoue, Y.U., Inoue, T., Masuyama, N., Obata, K., Yanagawa, Y., et al. (2009). Inhibitory and excitatory subtypes of cochlear nucleus neurons are defined by distinct bHLH transcription factors, Ptf1a and Atoh1. Development 136, 2049-2058. Green, M.J., Myat, A.M., Emmenegger, B.A., Wechsler-Reya, R.J., Wilson, L.J., and Wingate, R.J. (2014). Independently specified Atoh1 domains define novel developmental compartments in rhombomere 1. Development 141, 389-398.

Green, M.J., and Wingate, R.J.T. (2014). Developmental origins of diversity in cerebellar output nuclei. Neural Development 9.

Grothe, B. (2003). New roles for synaptic inhibition in sound localization. Nature reviews Neuroscience 4, 540-550.

Grothe, B., Carr, C.E., Casseday, J.H., Fritzsch, B., and Köppl, C. (2004). The evolution of central pathways and their neural processing patterns. In Evolution of Vertebrate Auditory System, G.A. Manley, A.N. Popper, and R.R. Fay, eds. (New York: Springer), pp. 289-359.

Grothe, B., and Pecka, M. (2014). The natural history of sound localization in mammals--a story of neuronal inhibition. Frontiers in neural circuits 8, 116.

Grothe, B., Pecka, M., and McAlpine, D. (2010). Mechanisms of sound localization in mammals. Physiological reviews 90, 983-1012.

Hadas, Y., Etlin, A., Falk, H., Avraham, O., Kobiler, O., Panet, A., Lev-Tov, A., and Klar, A. (2014). A 'tool box' for deciphering neuronal circuits in the developing chick spinal cord. Nucleic acids research 42, e148.

Hamburger, V.a.H., H. (1951). A series of normal stages in the development of the chick embryo. J Morphol 88, 49-92.

Helms, A.W., Abney, A.L., Ben-Arie, N., Zoghbi, H.Y., and Johnson, J.E. (2000). Autoregulation and multiple enhancers control Math1 expression in the developing nervous system. Development 127, 1185-1196.

Hendricks, S.J., Rubel, E.W., and Nishi, R. (2006). Formation of the avian nucleus magnocellularis from the auditory anlage. J Comp Neurol 498, 433-442. 
bioRxiv preprint doi: https://doi.org/10.1101/372243; this version posted July 18, 2018. The copyright holder for this preprint (which was not certified by peer review) is the author/funder, who has granted bioRxiv a license to display the preprint in perpetuity. It is made available under aCC-BY-NC-ND 4.0 International license.

Hudspeth, A.J. (2008). Making an effort to listen: mechanical amplification in the ear. Neuron 59, 530-545.

Jeffress, L.A. (1948). A place theory of sound localization. Journal of comparative and physiological psychology 41, 35-39.

Karino, S., Smith, P.H., Yin, T.C., and Joris, P.X. (2011). Axonal branching patterns as sources of delay in the mammalian auditory brainstem: a re-examination. The Journal of neuroscience : the official journal of the Society for Neuroscience 31, 3016-3031.

Kitazawa, T., Takechi, M., Hirasawa, T., Adachi, N., Narboux-Neme, N., Kume, H., Maeda, K., Hirai, T., Miyagawa-Tomita, S., Kurihara, Y., et al. (2015). Developmental genetic bases behind the independent origin of the tympanic membrane in mammals and diapsids. Nature communications 6 , 6853.

Kohl, A., Hadas, Y., Klar, A., and Sela-Donenfeld, D. (2012). Axonal patterns and targets of dA1 interneurons in the chick hindbrain. The Journal of neuroscience : the official journal of the Society for Neuroscience 32, 5757-5771.

Koppl, C. (2011). Birds--same thing, but different? Convergent evolution in the avian and mammalian auditory systems provides informative comparative models. Hearing research 273, 65-71. Kuenzel, W.J., and Masson, M. (1988). A stereotaxic atlas of the brain of the chick (Gallus domesticus) (Baltimore, MA: The John Hopkins University Press).

Lachica, E.A., Rubsamen, R., and Rubel, E.W. (1994). GABAergic terminals in nucleus magnocellularis and laminaris originate from the superior olivary nucleus. J Comp Neurol 348, 403-418.

Machold, R., and Fishell, G. (2005). Math1 is expressed in temporally discrete pools of cerebellar rhombic-lip neural progenitors. Neuron 48, 17-24.

Malinvaud, D., Vassias, I., Reichenberger, I., Rossert, C., and Straka, H. (2010). Functional organization of vestibular commissural connections in frog. The Journal of neuroscience : the official journal of the Society for Neuroscience 30, 3310-3325.

Manley, G.A. (2000). Cochlear mechanisms from a phylogenetic viewpoint. Proceedings of the National Academy of Sciences of the United States of America 97, 11736-11743.

Manley, G.A. (2017). Comparative Auditory Neuroscience: Understanding the Evolution and Function of Ears. Journal of the Association for Research in Otolaryngology : JARO 18, 1-24.

Manley, G.A., Popper, A.N., and Fay, R.R. (2004). Evolution of Vertebrate Auditory System (Springer: New York).

Manzanares, M., Bel-Vialar, S., Ariza-McNaughton, L., Ferretti, E., Marshall, H., Maconochie, M.M., Blasi, F., and Krumlauf, R. (2001). Independent regulation of initiation and maintenance phases of Hoxa3 expression in the vertebrate hindbrain involve auto- and cross-regulatory mechanisms.

Development 128, 3595-3607.

Maricich, S.M., Xia, A., Mathes, E.L., Wang, V.Y., Oghalai, J.S., Fritzsch, B., and Zoghbi, H.Y. (2009). Atoh1-lineal neurons are required for hearing and for the survival of neurons in the spiral ganglion and brainstem accessory auditory nuclei. The Journal of neuroscience : the official journal of the Society for Neuroscience 29, 11123-11133.

Marin, F., and Puelles, L. (1995). Morphological fate of rhombomeres in quail/chick chimeras: a segmental analysis of hindbrain nuclei. The European journal of neuroscience 7, 1714-1738.

Marrs, G.S., Morgan, W.J., Howell, D.M., Spirou, G.A., and Mathers, P.H. (2013). Embryonic origins of the mouse superior olivary complex. Developmental neurobiology 73, 384-398.

Marrs, G.S., and Spirou, G.A. (2012). Embryonic assembly of auditory circuits: spiral ganglion and brainstem. J Physiol 590, 2391-2408.

Meredith, D.M., Masui, T., Swift, G.H., MacDonald, R.J., and Johnson, J.E. (2009). Multiple transcriptional mechanisms control Ptf1a levels during neural development including autoregulation by the PTF1-J complex. The Journal of neuroscience : the official journal of the Society for Neuroscience 29, 11139-11148.

Morrison, A., Ariza-McNaughton, L., Gould, A., Featherstone, M., and Krumlauf, R. (1997). HOXD4 and regulation of the group 4 paralog genes. Development 124, 3135-3146. 
bioRxiv preprint doi: https://doi.org/10.1101/372243; this version posted July 18, 2018. The copyright holder for this preprint (which was not certified by peer review) is the author/funder, who has granted bioRxiv a license to display the preprint in perpetuity. It is made available under aCC-BY-NC-ND 4.0 International license.

Myat, A., Henrique, D., Ish-Horowicz, D., and Lewis, J. (1996). A chick homologue of Serrate and its relationship with Notch and Delta homologues during central neurogenesis. Developmental biology 174, 233-247.

Myoga, M.H., Lehnert, S., Leibold, C., Felmy, F., and Grothe, B. (2014). Glycinergic inhibition tunes coincidence detection in the auditory brainstem. Nature communications 5, 3790.

Nieuwenhuys, R. (2011). The structural, functional, and molecular organization of the brainstem. Front Neuroanat 5, 33.

Pasqualetti, M., Diaz, C., Renaud, J.S., Rijli, F.M., and Glover, J.C. (2007). Fate-mapping the mammalian hindbrain: segmental origins of vestibular projection neurons assessed using rhombomere-specific Hoxa2 enhancer elements in the mouse embryo. The Journal of neuroscience : the official journal of the Society for Neuroscience 27, 9670-9681.

Passetto, M.F., Britto, L.R., and Toledo, C.A. (2008). Morphometric analysis of the AMPA-type neurons in the Deiter's vestibular complex of the chick brain. Journal of chemical neuroanatomy 35 , 334-345.

Petursdottir, G. (1990). Vestibulo-ocular projections in the 11-day chicken embryo: pathway specificity. J Comp Neurol 297, 283-297.

Philippidou, P., and Dasen, J.S. (2013). Hox genes: choreographers in neural development, architects of circuit organization. Neuron 80, 12-34.

Rose, M.F., Ahmad, K.A., Thaller, C., and Zoghbi, H.Y. (2009). Excitatory neurons of the proprioceptive, interoceptive, and arousal hindbrain networks share a developmental requirement for Math1. Proceedings of the National Academy of Sciences of the United States of America 106, 22462-22467.

Ryugo, D.K., and Parks, T.N. (2003). Primary innervation of the avian and mammalian cochlear nucleus. Brain research bulletin 60, 435-456.

Sassa, T., Aizawa, H., and Okamoto, H. (2007). Visualization of two distinct classes of neurons by gad2 and zic1 promoter/enhancer elements in the dorsal hindbrain of developing zebrafish reveals neuronal connectivity related to the auditory and lateral line systems. Developmental dynamics : an official publication of the American Association of Anatomists 236, 706-718.

Smith, P.H., Joris, P.X., and Yin, T.C. (1993). Projections of physiologically characterized spherical bushy cell axons from the cochlear nucleus of the cat: evidence for delay lines to the medial superior olive. J Comp Neurol 331, 245-260.

Soares, D., and Carr, C.E. (2001). The cytoarchitecture of the nucleus angularis of the barn owl (Tyto alba). J Comp Neurol 429, 192-205.

Soares, D., Chitwood, R.A., Hyson, R.L., and Carr, C.E. (2002). Intrinsic neuronal properties of the chick nucleus angularis. Journal of neurophysiology 88, 152-162.

Straka, H., and Baker, R. (2013). Vestibular blueprint in early vertebrates. Frontiers in neural circuits 7, 182.

Straka, H., Baker, R., and Gilland, E. (2002). The frog as a unique vertebrate model for studying the rhombomeric organization of functionally identified hindbrain neurons. Brain research bulletin 57, 301-305.

Straka, H., Fritzsch, B., and Glover, J.C. (2014). Connecting ears to eye muscles: evolution of a 'simple' reflex arc. Brain, behavior and evolution 83, 162-175.

Tabor, K.M., Coleman, W.L., Rubel, E.W., and Burger, R.M. (2012). Tonotopic organization of the superior olivary nucleus in the chicken auditory brainstem. J Comp Neurol 520, 1493-1508.

Takahashi, T.T., and Konishi, M. (1988). Projections of the cochlear nuclei and nucleus laminaris to the inferior colliculus of the barn owl. J Comp Neurol 274, 190-211.

Tan, K., and Le Douarin, N.M. (1991). Development of the nuclei and cell migration in the medulla oblongata. Application of the quail-chick chimera system. Anatomy and embryology 183, 321-343. Tomas-Roca, L., Corral-San-Miguel, R., Aroca, P., Puelles, L., and Marin, F. (2016). Cryptorhombomeres of the mouse medulla oblongata, defined by molecular and morphological features. Brain structure \& function 221, 815-838. 
Tucker, A.S. (2017). Major evolutionary transitions and innovations: the tympanic middle ear. Philosophical transactions of the Royal Society of London Series B, Biological sciences 372.

Walton, P.L., Christensen-Dalsgaard, J., and Carr, C.E. (2017). Evolution of Sound Source Localization Circuits in the Nonmammalian Vertebrate Brainstem. Brain, behavior and evolution 90, 131-153. Wang, V.Y., Rose, M.F., and Zoghbi, H.Y. (2005). Math1 expression redefines the rhombic lip derivatives and reveals novel lineages within the brainstem and cerebellum. Neuron 48, 31-43. Whitfield, T.T. (2015). Development of the inner ear. Current opinion in genetics \& development 32, 112-118.

Wild, J.M., Krutzfeldt, N.O., and Kubke, M.F. (2010). Connections of the auditory brainstem in a songbird, Taeniopygia guttata. III. Projections of the superior olive and lateral lemniscal nuclei. J Comp Neurol 518, 2149-2167.

Wilson, L.J., and Wingate, R.J. (2006). Temporal identity transition in the avian cerebellar rhombic lip. Developmental biology 297, 508-521.

Wold, J.E. (1976). The vestibular nuclei in the domestic hen (Gallus domesticus). I. Normal anatomy. Anatomy and embryology 149, 29-46.

Wullimann, M.F., Mueller, T., Distel, M., Babaryka, A., Grothe, B., and Koster, R.W. (2011). The long adventurous journey of rhombic lip cells in jawed vertebrates: a comparative developmental analysis. Front Neuroanat 5, 27.

Yamada, M., Terao, M., Terashima, T., Fujiyama, T., Kawaguchi, Y., Nabeshima, Y., and Hoshino, M. (2007). Origin of climbing fiber neurons and their developmental dependence on Ptf1a. The Journal of neuroscience : the official journal of the Society for Neuroscience 27, 10924-10934. 
bioRxiv preprint doi: https://doi.org/10.1101/372243; this version posted July 18, 2018. The copyright holder for this preprint (which was not certified by peer review) is the author/funder, Bho has granted bioRxiv a license to display the preprint in perpetuity. It is made available under aCC-BY-NC-ND 4.0 International license.
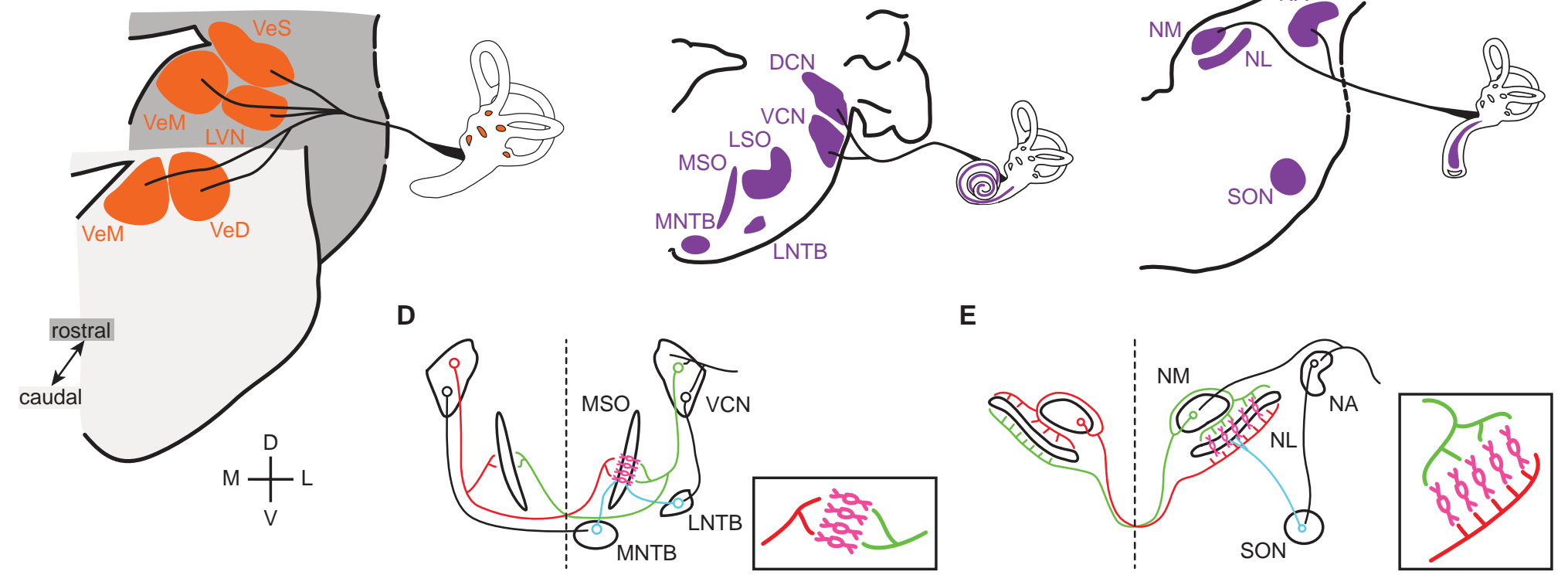

E

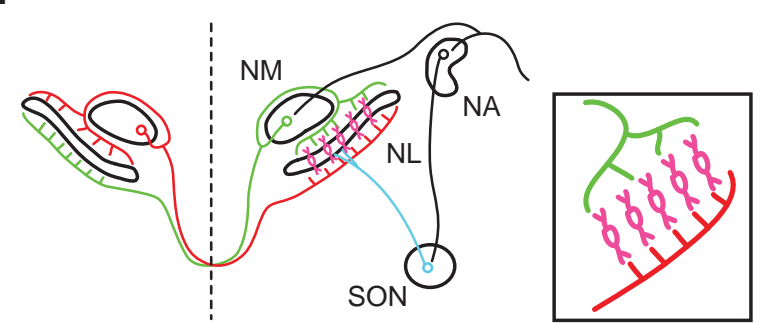

Figure 1. Vestibular and auditory brainstem nuclei of mammals and birds.

A. Schematic diagrams of hindbrain coronal sections showing the 4 main vestibular nuclei of vertebrates that receive direct input form the VIIIth (vestibular) nerve. VeS, Superior Vestibular Nucleus; LVN, Lateral Vestibular Nucleus (Deiter's Nucleus); VeM, Medial Vestibular Nucleus; VeD, Descending Vestibular Nucleus (Spinal or Inferior Vestibular Nucleus). D, dorsal; V, ventral; M, medial; L, lateral. B-C. Schematic diagrams of hindbrain coronal sections depicting the mammalian (B) and avian (C) hindbrain first order auditory nuclei that receive direct input from the VIIIth (auditory) nerve and the main second order nuclei to which they project. DCN, Dorsal Cochlear Nucleus; VCN, Ventral Cochlear Nucleus; LSO, Lateral Superior Olive; MSO, Medial Superior Olive; MNTB, Medial Nucleus of the Trapezoid Body; LNTB, Lateral Nucleus of the Trapezoid Body; NA, Nucleus Angularis; NM, Nucleus Magnocellularis; NL, Nucleus Lateralis; SON, Superior Olivary Nucleus. D-E. Schematic representation of the main connections of the mammalian (D) and avian (E) ITD circuits. Insets. Close-up view of the coincidence detection neurons showing the arrangement of ipsilateral and contralateral connections. Bilateral projection neurons, red and green. Coincidence detection neurons, magenta. Inhibitory neurons, cyan. Auditory nerve inputs and inhibitory connections are drawn only on the right side for simplicity. 

not certified by peer review) is the author/funder, who has granted bioRxiv a license to display the preprint in perpetuity. It is made

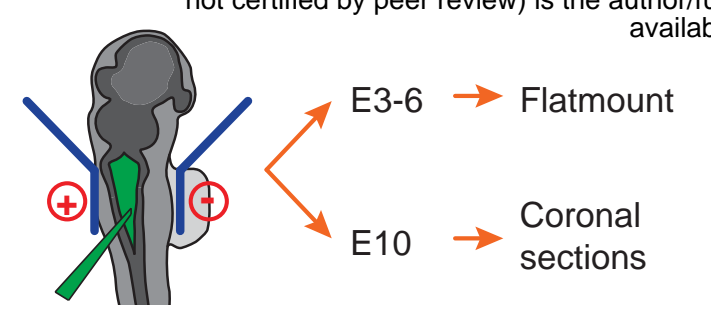
available under aCC-BY-NC-ND 4.0 International license.

C

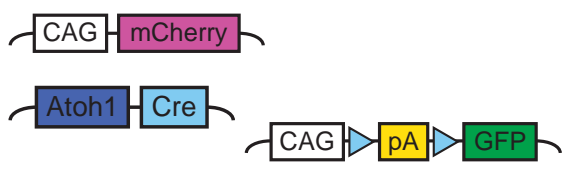

Atoh1 I mCh

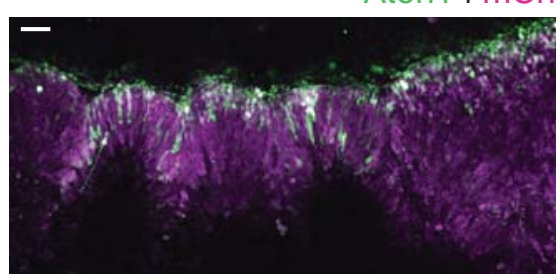

D
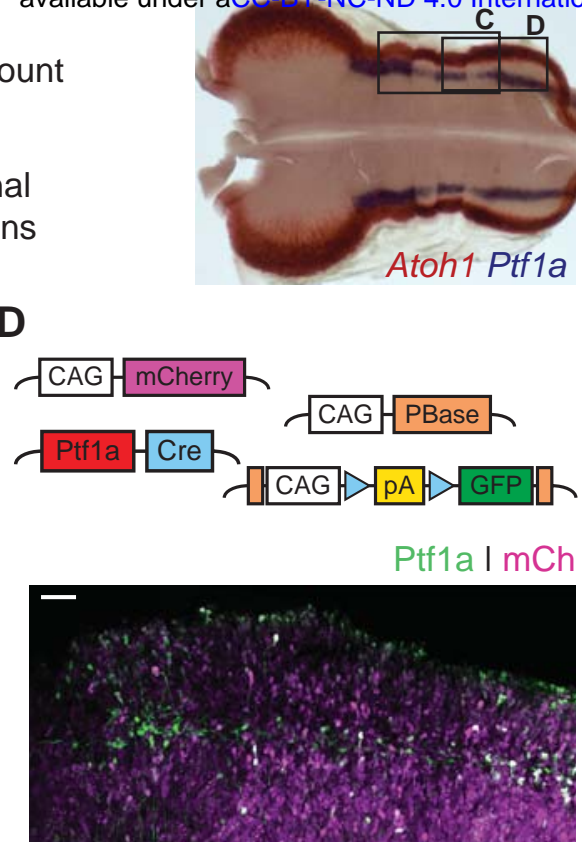

E

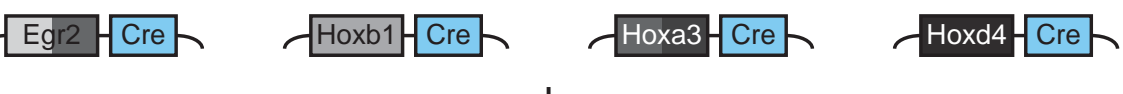

$+$

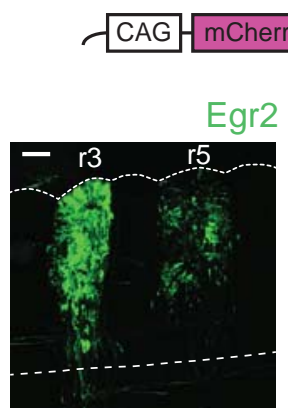

$+\sqrt{\mathrm{CAG}} \mathrm{PBase}+\lambda \mathrm{CAG} \gg \mathrm{PA} D \mathrm{GFP}$

Egr2 I mCh
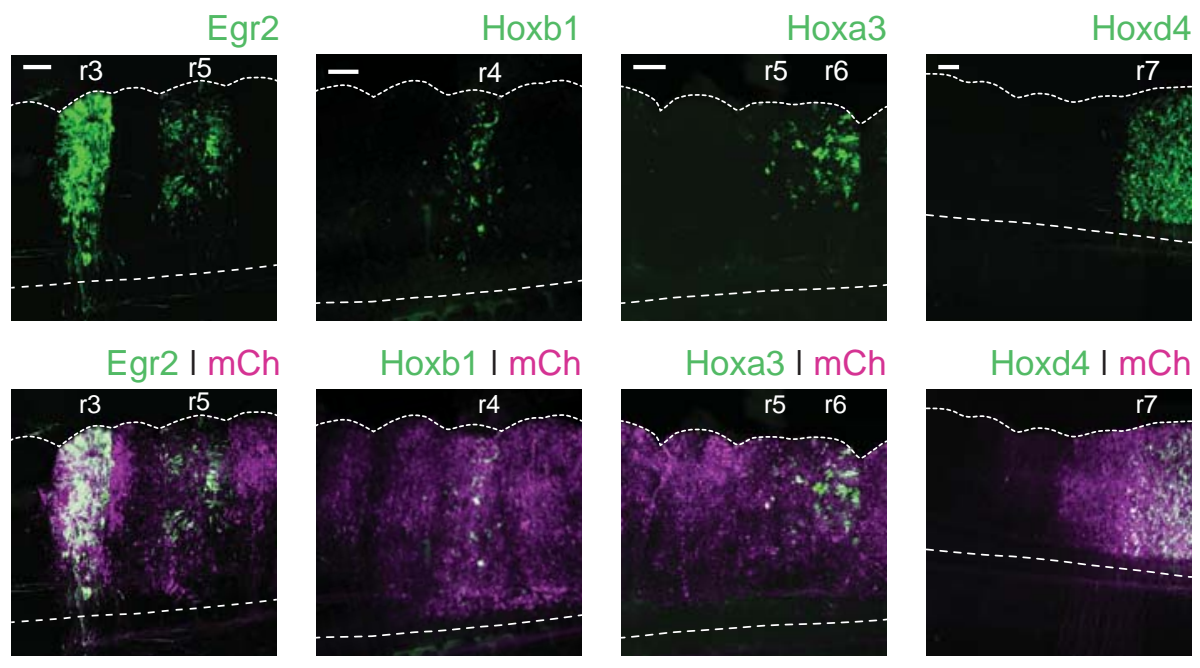

$\mathrm{Hoxd} 4 \mathrm{I} \mathrm{mCh}$

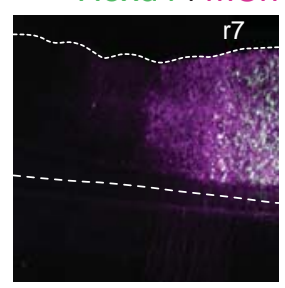

Figure 2. Fate mapping the developmental origin of hindbrain auditory and vestibular nuclei.

A. Diagram of the electroporation strategy. B. Representative flatmount view of a HH21 chick hindbrain stained by in situ hybridisation for Atoh1 (red) and Ptf1a (blue). C-D. Top panels. Plasmid constructs employed for labelling Atoh1 ${ }^{+}$(C) and Ptf1a ${ }^{+}$ (D) progenitors. Bottom panels. Representative close up flatmount image of $\mathrm{HH} 17$ chick hindbrains, electroporated at $\mathrm{HH} 14$ with Atoh1-Cre + CAG-Flox-pA-GFP + CAG-mCherry (C) or Ptf1a1-Cre + CAG-PBase + Pb-CAG-Flox-pA-GFP + CAG-mCherry (D). Scale bar: $50 \mu \mathrm{m}$. E. Top panels. Plasmid constructs employed for labelling cells arising from specific rhombomeres. Bottom panels. Representative close up flatmount images of $\mathrm{HH} 17$ ( $\mathrm{HH} 28$ for Hoxd4) chick hindbrains, electroporated at $\mathrm{HH} 14$ with CAG-PBase + Pb-CAG-Flox-pA-GFP + CAG-mCherry and Egr2-Cre, Hoxb1-Cre, Hoxa3-Cre or Hoxd4-Cre, from left to right, respectively. Dotted lines outline the lateral border and the ventral midline. Scale bar: $100 \mu \mathrm{m}$. 

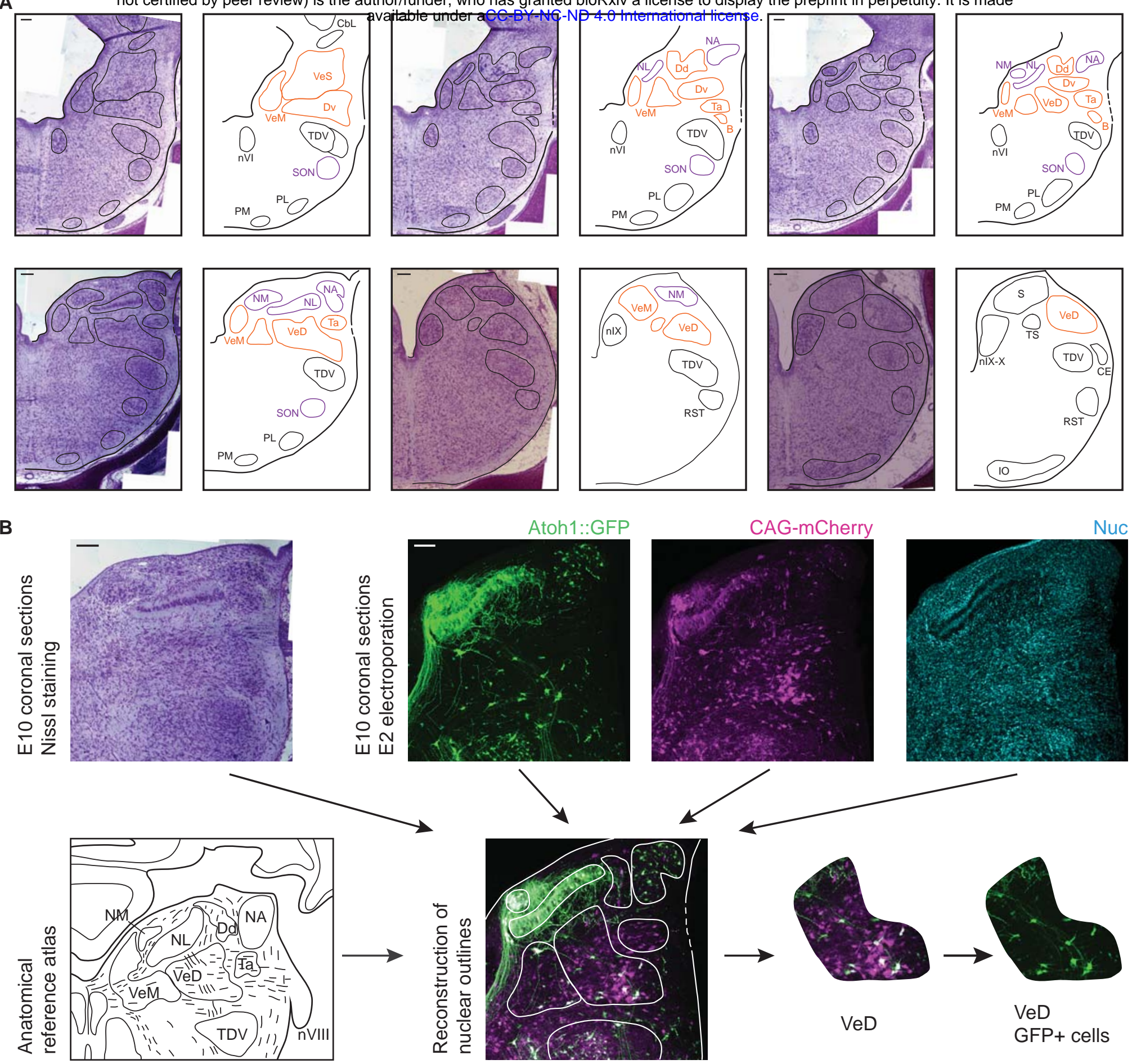

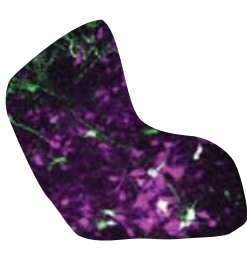

VeD

Nuc

Figure 3. Anatomy of hindbrain auditory and vestibular nuclei.

A. Representative images of coronal sections of Nissl stained E10 chick hindbrain (left panels) and diagrams (right panels), showing the outlines of hindbrain nuclei. From left to right and top to bottom: rostral to caudal. Scale bars: $50 \mu \mathrm{m}$. All drawings are to scale. B, Cell group B; Cbl, Nucleus Cerebellaris Internus; CE, Nucleus Cuneatus Externus; Dd, Nucleus Deiters Dorsalis; Dv, Nucleus Deiters Ventralis; IO, Inferior Olive Nucleus; NA, Nucleus Angularis; nIX, Glossopharyngeal Nucleus; nIX-X, Glossopharyngei and Vagus Nucleus; NL, Nucleus Lateralis; NM, Nucleus Magnocellularis; nVI, Abducens Nucleus; PL, Lateral Pontine Nucleus; PM, Medial Pontine Nucleus; RST, Reticular Subtrigeminal Nucleus; S, Solitaris Nucleus; SON, Superior Olivary Nucleus; Ta, Tangential Nucleus; TDV, Descending Trigeminal Nucleus; TS, Torus Semicircularis; VeD, Descending Vestibular Nucleus; VeM, Medial Vestibular Nucleus; VeS, Superior Vestibular Nucleus. B. Example of a nucleus identification by combining information from Nissl stained sections (top left), fluorescent protein expression and nuclear staining (top right) and anatomical reference atlases (bottom left, modified from (Kuenzel and Masson, 1988; Wold, 1976)). 

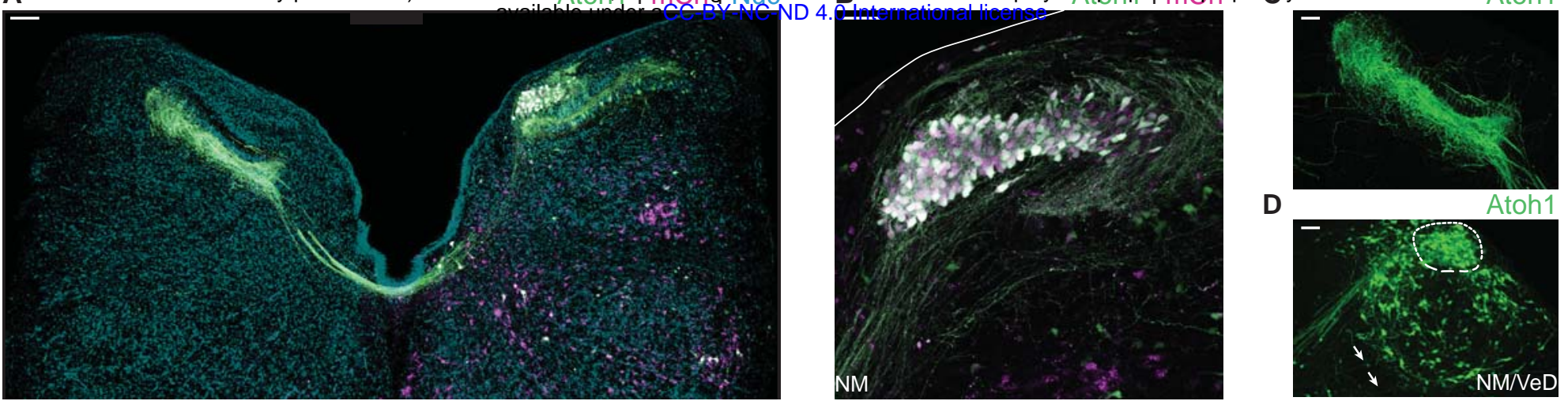

D

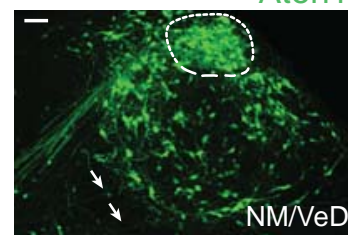

E
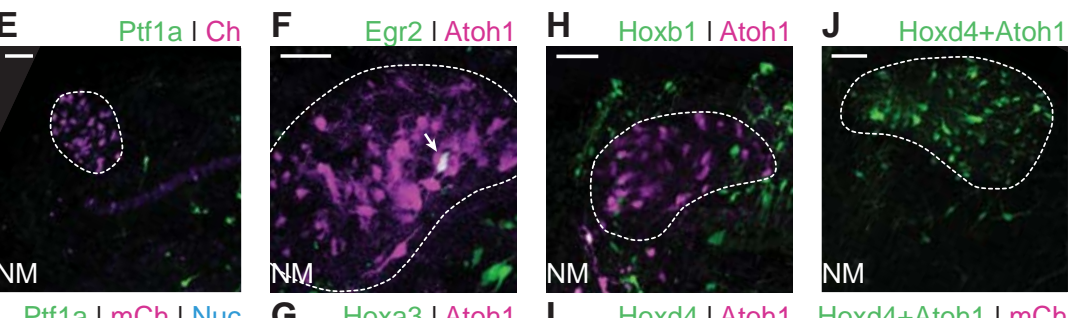

K
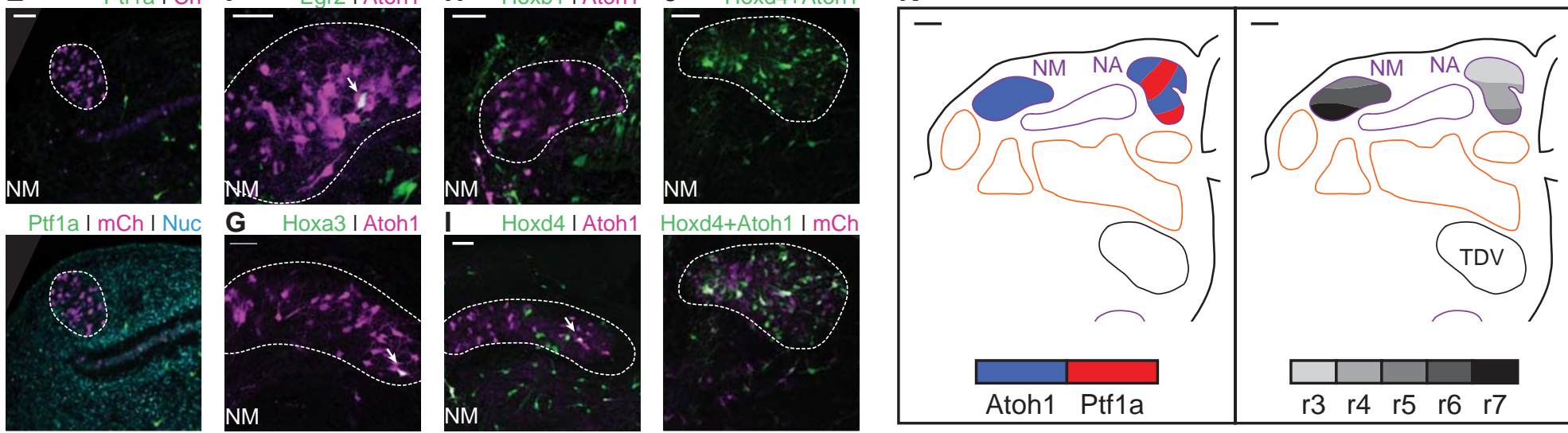

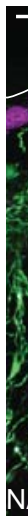

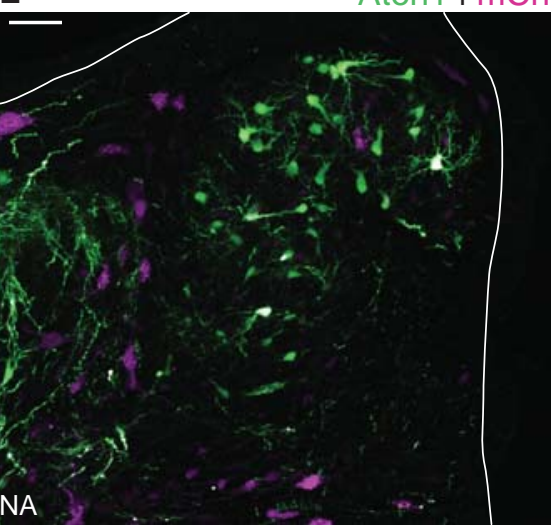

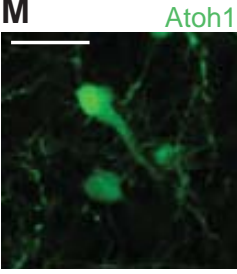

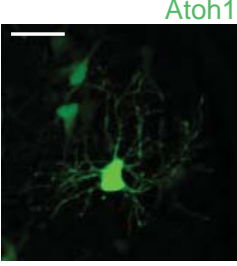

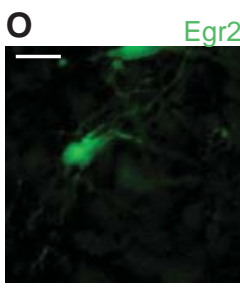

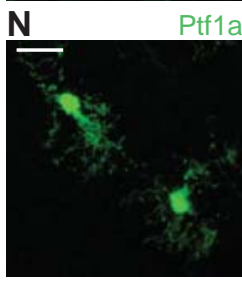

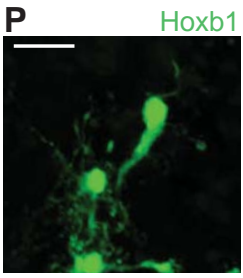
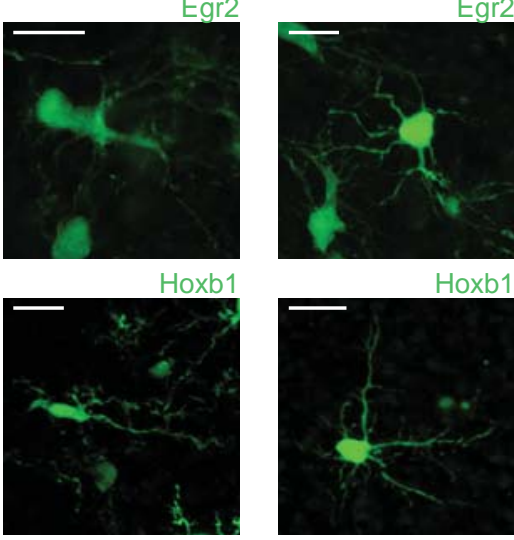

Figure 4. Developmental origin of chick first order hindbrain auditory nuclei.

A. Representative image of an E10 chick hindbrain coronal section electroporated at HH14 with Atoh1-Cre + CAG-Flox-pA-GFP (Atoh1::GFP) and CAG-mCherry. Scale bar: $100 \mu \mathrm{m}$. B. Close up view of the NM from a section caudal to the one shown in A. Solid line, hindbrain border. Scale bar: $50 \mu \mathrm{m}$. C. Close up view of Atoh1+ NM projections to the contralateral NL. Scale bar: $50 \mu \mathrm{m}$. D. Close up view of the caudal NM showing a diffuse boundary with the VeD. Dotted line shows NM border. Arrows show VeD projections that join the contralateral NM axons. Scale bar: $50 \mu \mathrm{m}$. E. Close up view of the NM from an E10 chick hindbrain coronal section electroporated at HH14 with Ptf1a-Cre, PBase, Pb-CAG-Flox-pA-GFP (Ptf1a::GFP) and CAG-mCherry. Dotted line shows NM border. Scale bar: $50 \mu \mathrm{m}$. F-I. Close up view of the NM from E10 chick hindbrain coronal sections electroporated at HH14 with CAG-PBase + Pb-CAG-Flox-pA-GFP + Atoh1-Gal4 + UAS-tdT (Atoh1::tdT) and Egr2-Cre (F), Hoxa3-Cre (G), Hoxb1-Cre (H) or Hoxd4-Cre (I). Scale bars: $50 \mu \mathrm{m}$. Arrows point to Egr2 ${ }^{+} /$Atoh1 $^{+}(\mathbf{F}), \mathrm{Hoxa3}^{+} / \mathrm{Atoh}^{+}(\mathbf{G})$ and Hoxd4 ${ }^{+} /$Atoh $^{+}$(I) cells. J. Close up view of the NM from an E10 chick hindbrain coronal section electroporated at HH14 with Hoxd4-Cre + Atoh1-FLPo + CAG-Flox-FLp-pA-GFP + CAG-mCherry. Dotted line shows NM border. Scale bar: 50 um. K. Diagrams summarising the contributions of Atoh1 ${ }^{+} / \mathrm{Ptfla}^{+}$progenitors (left panel) or different rhombomeres (right panel) to the first order auditory nuclei. Scale bars: $50 \mu \mathrm{m}$. L. Close up view of the NA from an E10 chick hindbrain coronal section electroporated at HH14 with Atoh1::GFP and CAG-mCherry. Solid lines, hindbrain borders. Scale bar: 50 um. M. Close up views of representative vertical (top-left panel), planar (top-right panel) and radial (bottom panel) NA Atoh1 ${ }^{+}$cells. Scale bars: $25 \mu \mathrm{m}$. N. Close up view of representative stubby NA Ptf1a+ cells. Scale bar: $20 \mu \mathrm{m}$. O. Close up views of representative vertical, (left panel), planar (middle panel) and radial (right panel) NA Egr2 ${ }^{+}$cells. Scale bars: $20 \mu \mathrm{m}$. P. Close up views of representative vertical and stubby, (left panel), planar (middle panel) and radial (right panel) NA Hoxb1 ${ }^{+}$cells. Scale bars: $20 \mu \mathrm{m}$. 


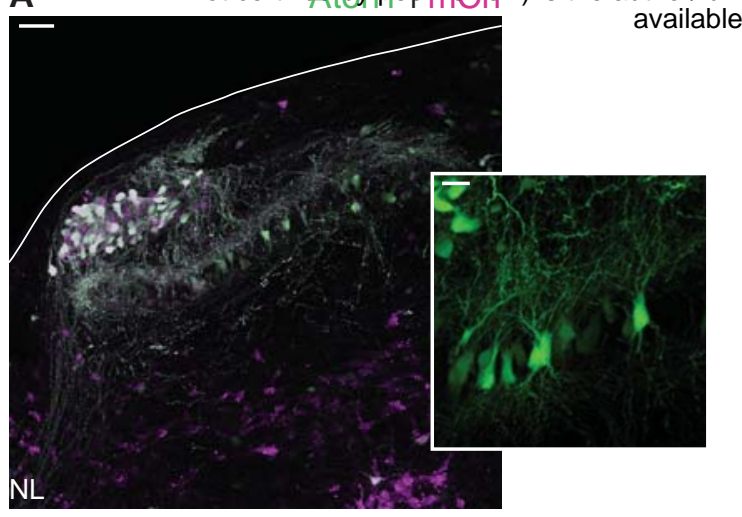

F Atoh1 I mCh

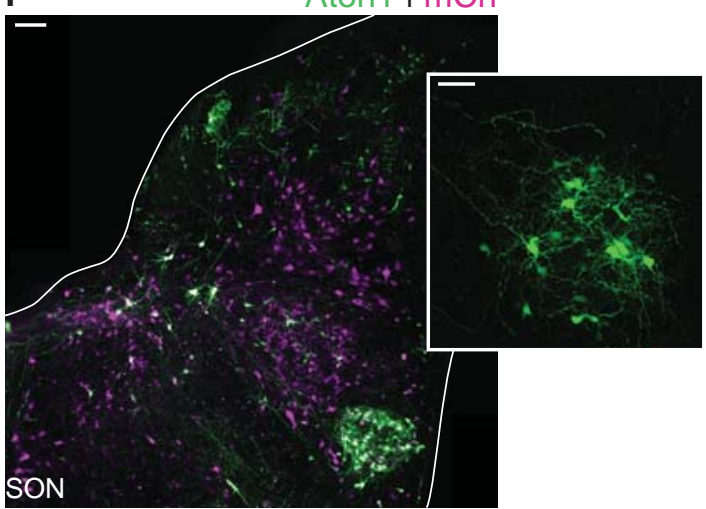

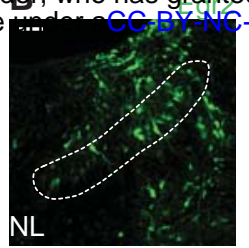

Egr2 I Nuc
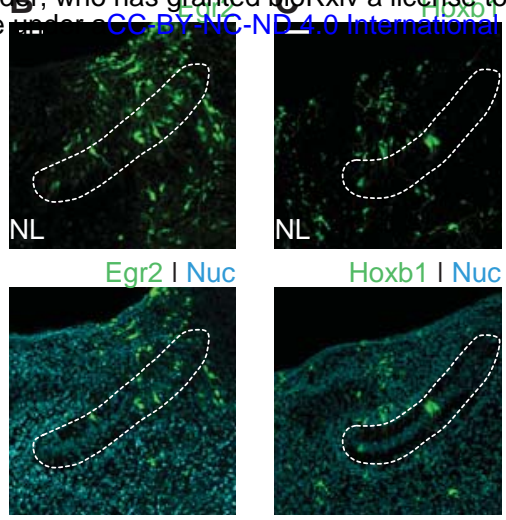

Hoxb1 I Nuc
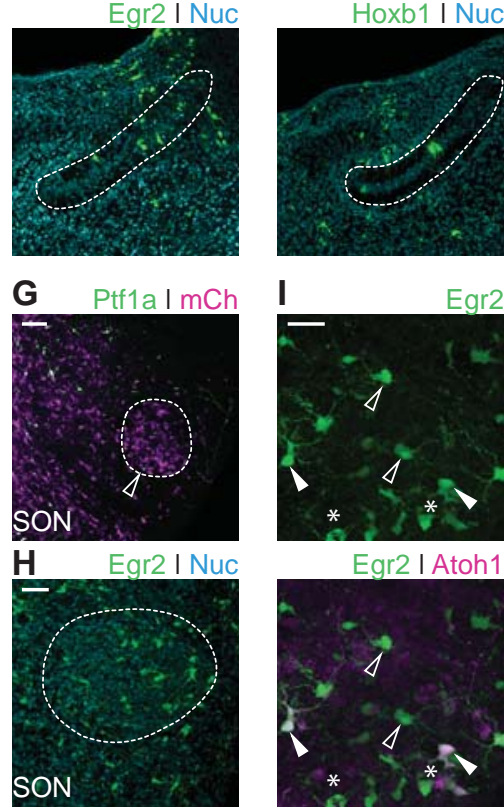
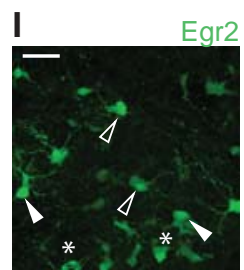

Egr2 | Atoh1

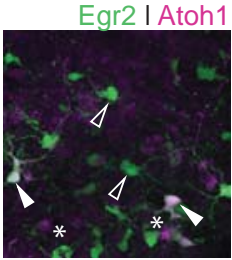

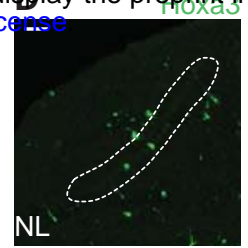

Hoxa3 I Nuc

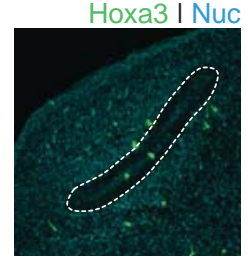

J Hoxb1 I Nuc
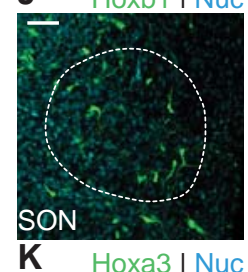

K

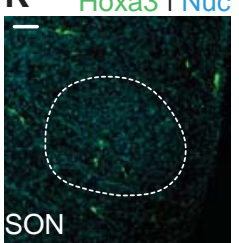

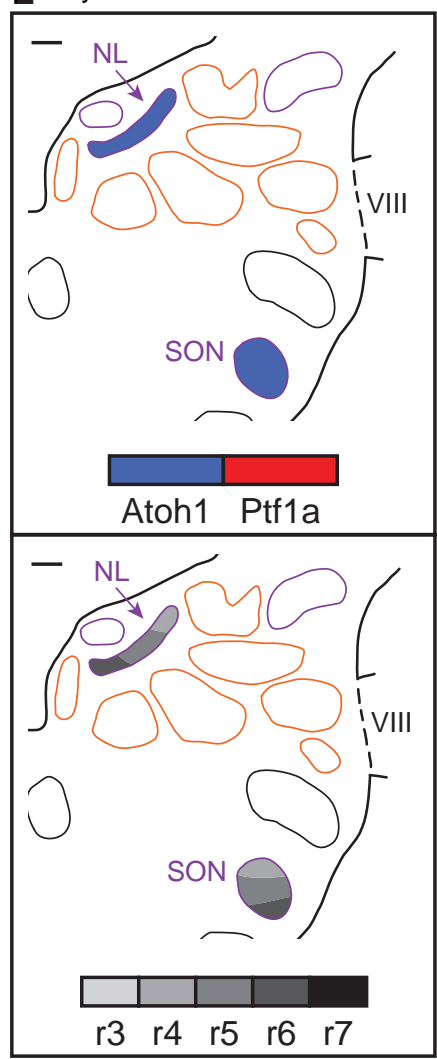

Figure 5. Developmental origin of avian second order hindbrain auditory nuclei.

A. Close up view of the NL from an E10 chick hindbrain coronal section electroporated at HH14 with Atoh1::GFP and CAG-mCherry. Solid line, dorsal border of the hindbrain. Scale bar: $50 \mu \mathrm{m}$. Inset: detailed view of Atoh1 ${ }^{+} \mathrm{NL}$ cells depicting bipolar morphology. Scale bar: $20 \mu \mathrm{m}$. B-D. Close up view of the NL from E10 chick hindbrain coronal sections electroporated at HH14 with Egr2::GFP (B), Hoxb1::GFP (C), Hoxa3::GFP (D) and counterstained with NucRed. Dotted lines show NL borders. Scale bars: $50 \mu \mathrm{m}$. E. Diagrams summarising the contributions of Atoh $1^{+} / \mathrm{Ptf} \mathrm{a}^{+}$progenitors (top panel) or different rhombomeres (bottom panel) to the second order auditory nuclei. Scale bars: $50 \mu \mathrm{m}$. F. Close up view of the SON from an E10 chick hindbrain coronal section electroporated at HH14 with Atoh1::GFP and CAG-mCherry. Solid lines, hindbrain borders. Scale bar: $100 \mu \mathrm{m}$. Inset: detailed view of Atoh1+ SON. Scale bar: $50 \mu \mathrm{m}$. G. Close up view of the SON from an E10 chick hindbrain coronal section electroporated at HH14 with Ptf1a::GFP and CAG-mCherry. Dotted line shows SON border. Scale bar: $100 \mu \mathrm{m}$. H. Close up view of the SON from an E10 chick hindbrain coronal section electroporated at HH14 with Egr2::GFP and counterstained with NucRed. Dotted line shows SON border. Scale bar: $50 \mu \mathrm{m}$. I. Close up view of the SON from an E10 chick hindbrain coronal section electroporated at HH14 with Egr2::GFP and Atoh1::tdT. Filled arrowheads show Egr2 ${ }^{+} /$Atoh1 ${ }^{+}$cells; empty arrowheads show Egr2 ${ }^{+}$/Atoh1 ${ }^{-}$cells; asterisks show Egr2-Atoh1 ${ }^{+}$cells. Scale bar: $50 \mu \mathrm{m}$. J-K. Close up view of the SON from E10 chick hindbrain coronal sections electroporated at HH14 with Hoxb1::GFP (J) or Hoxa3::GFP (K) and counterstained with NucRed. Dotted lines show SON borders. Scale bars: $50 \mu \mathrm{m}$. 


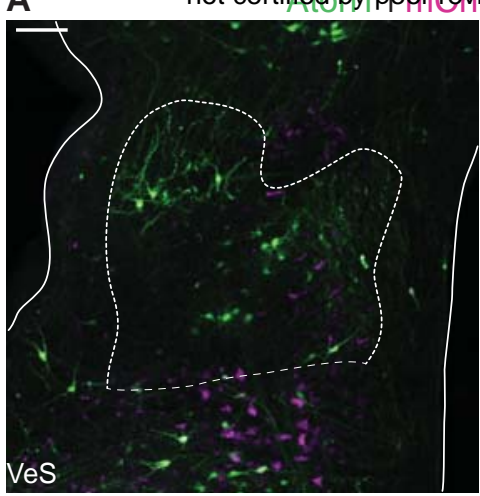

E

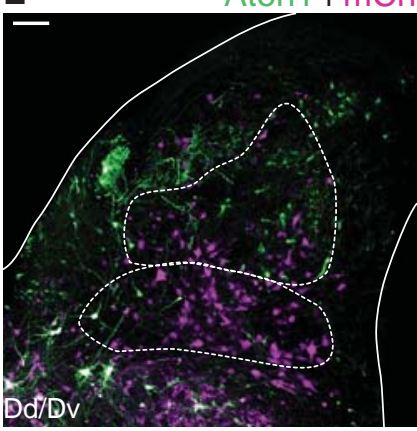

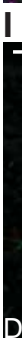

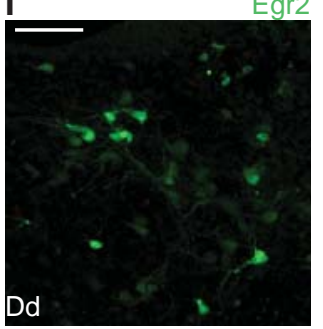

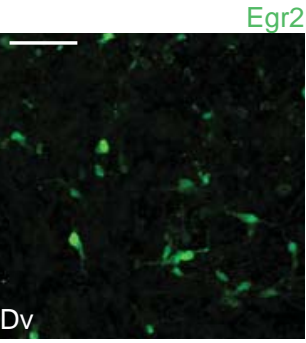

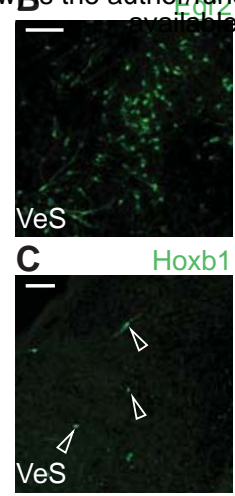

$F$
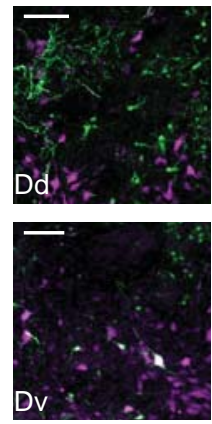$$
\text { J }
$$

G
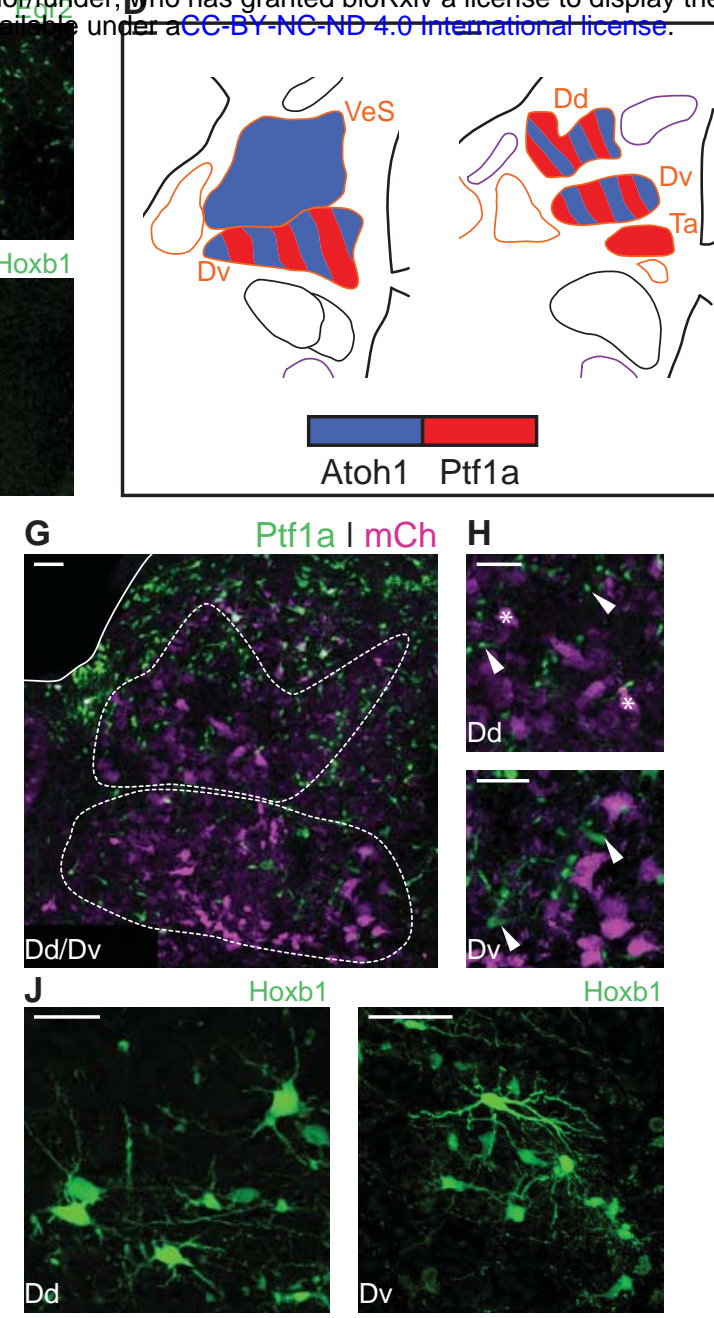
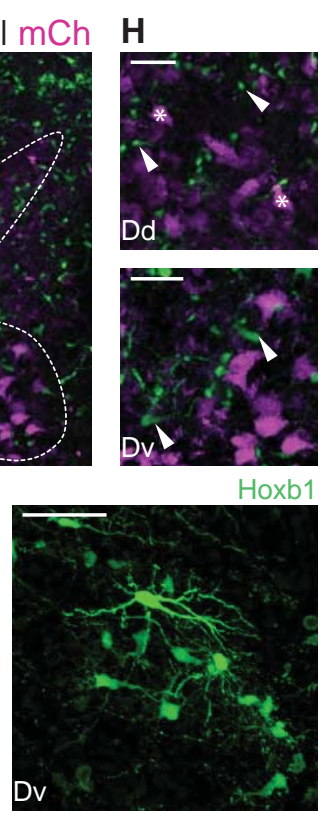

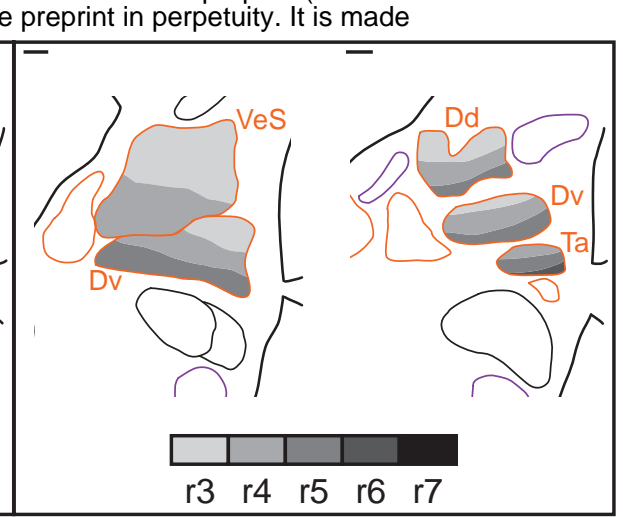

K
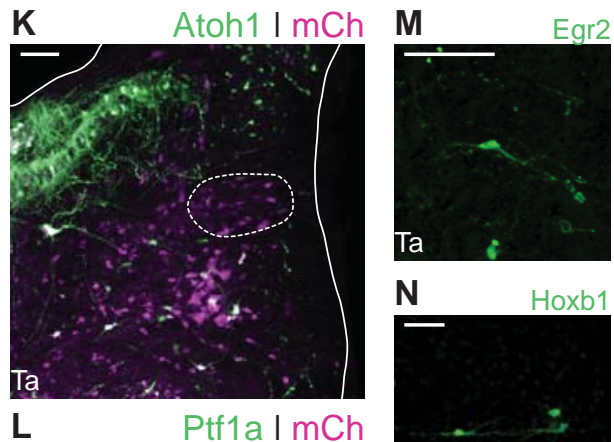

N

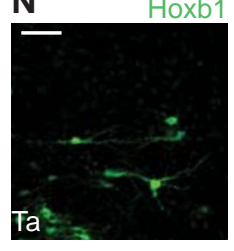

0

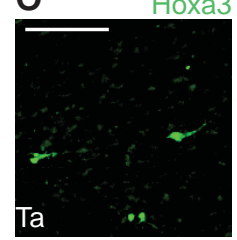

Figure 6. Developmental origin of avian Superior, Deiters and Tangential vestibular nuclei.

A. Close up view of the VeS from an E10 chick hindbrain coronal section electroporated at HH14 with Atoh1::GFP and CAG-mCherry. Solid lines, hindbrain. Dotted lines, VeS borders. Scale bar: $100 \mu \mathrm{m}$. B-C. Close up view of the VeS from an E10 chick hindbrain coronal section electroporated at HH14 with Egr2::GFP (B) or Hoxb1::GFP (C). Scale bars: 100 um. D. Diagrams summarising the contributions of Atoh $1^{+} / \mathrm{Ptf1} \mathrm{a}^{+}$progenitors (left panel) or different rhombomeres (right panel) to the superior, deiters and tangential vestibular nuclei. Scale bars: $50 \mu \mathrm{m}$. E. Close up view of the Dd and Dv from an E10 chick hindbrain coronal section electroporated at HH14 with Atoh1::GFP and CAG-mCherry. Solid lines, hindbrain borders. Dotted lines, Dd and Dv borders. Scale bar: $100 \mu \mathrm{m}$. F. Detailed view of Atoh $1^{+}$cells in the Dd (top panel) and the Dv (bottom panel). Scale bars: 100 $\mu \mathrm{m}$. G. Close up view of the Dd and Dv from an E10 chick hindbrain coronal section electroporated at HH14 with Ptf1a::GFP and CAG-mCherry. Solid line, hindbrain borders. Dotted lines, Dd and Dv borders. Scale bar: $50 \mu \mathrm{m}$. H. Detailed view of Ptf1a+ cells in the Dd (top panel) and the Dv (bottom panel). Scale bars: $50 \mu \mathrm{m}$. I-J. Detailed view of Egr2 ${ }^{+}(\mathrm{I})$ and Hoxb1 $1^{+}(\mathrm{J})$ cells in the Dd (left panel) and the Dv (right panel). Scale bars: $50 \mu \mathrm{m}$. K. Close up view of the Ta from an E10 chick hindbrain coronal section electroporated at HH14 with Atoh1::GFP and CAG-mCherry. Solid lines, hindbrain borders. Dotted line, Ta borders. Scale bar: $100 \mu \mathrm{m}$. L. Close up view of the Ta from an E10 chick hindbrain coronal section electroporated at HH14 with

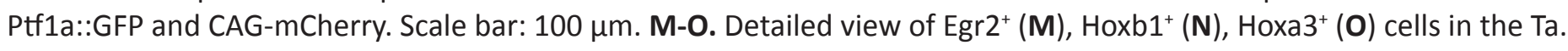
Scale bars: 50, 100 and $100 \mu \mathrm{m}$, respectively. 


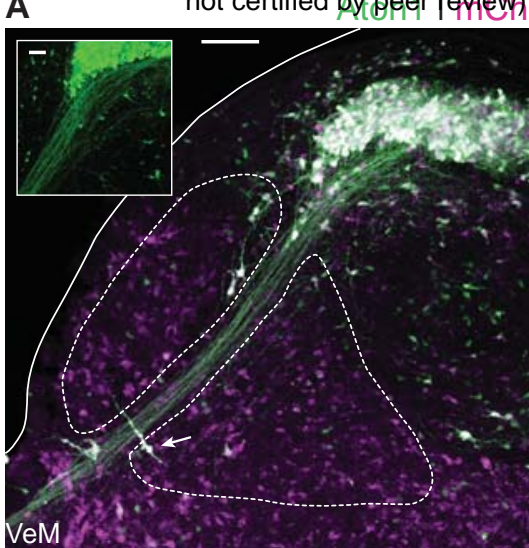

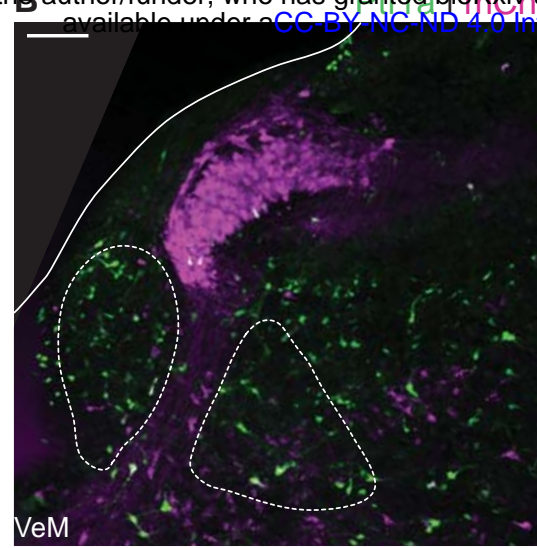

$\mathrm{H}$
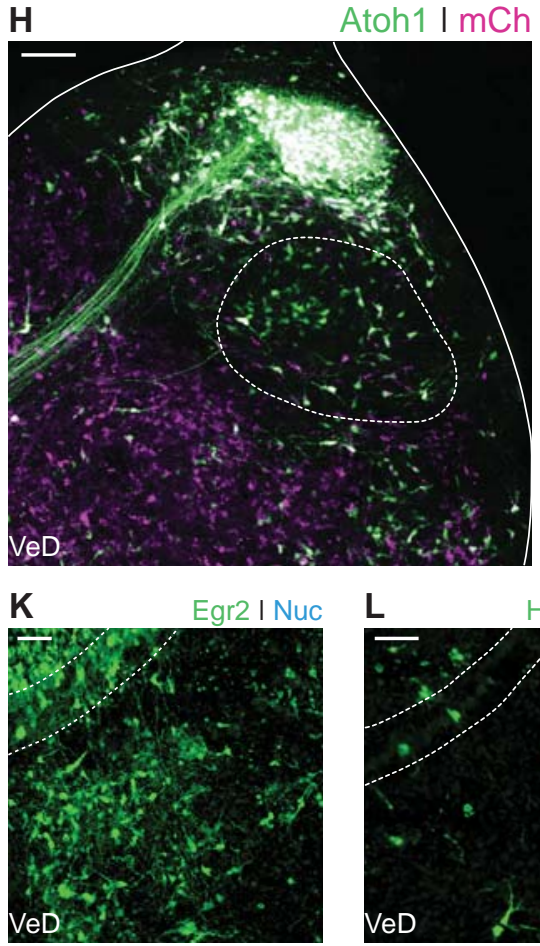
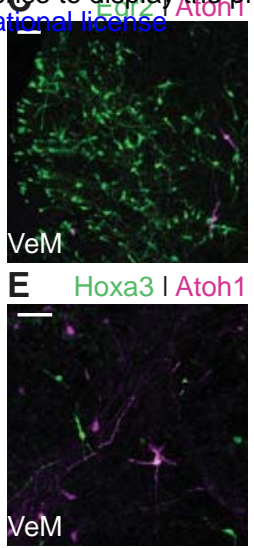

I
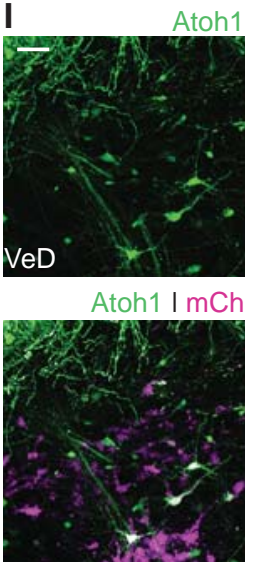

L

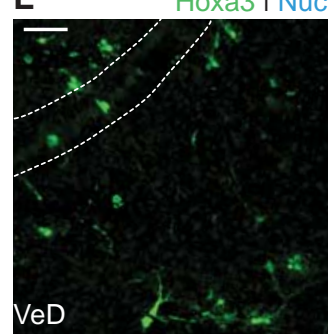

M

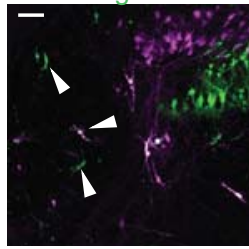

F Hoxd4|Atoh1

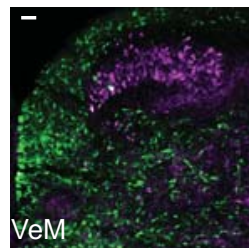

J
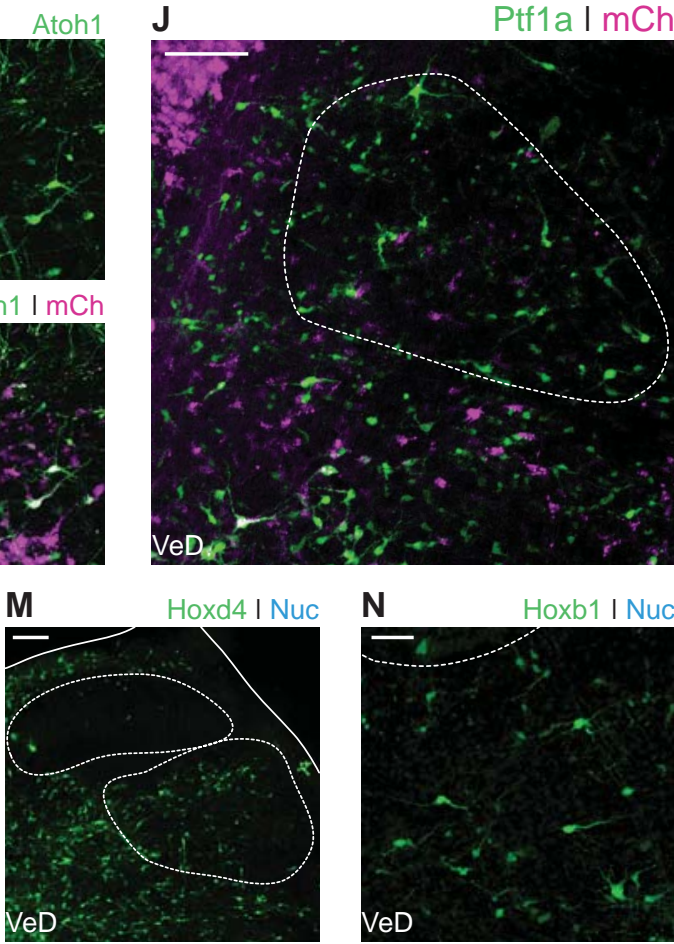

$\mathbf{N}$

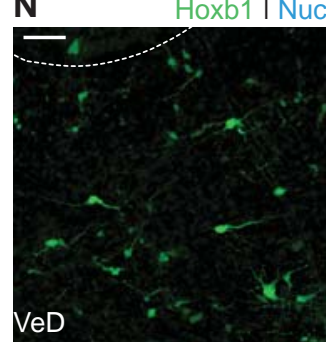

Figure 7. Developmental origin of avian Medial and Descending vestibular nuclei.

A. Close up view of the VeM from an E10 chick hindbrain coronal section electroporated at HH14 with Atoh1::GFP and CAG-mCherry. Scale bar: $100 \mu \mathrm{m}$. Inset: detailed view of VeM Atoh1+ cells. Solid line, hindbrain border. Dotted lines, VeM borders. Scale bar: $50 \mu \mathrm{m}$. B. Close up view of the VeM from an E10 chick hindbrain coronal section electroporated at HH14 with Ptf1a::GFP and CAG-mCherry. Solid line, hindbrain border. Dotted lines, VeM borders. Scale bar: $100 \mu \mathrm{m}$. C-F. Close up view of the VeM from E10 chick hindbrain coronal sections electroporated at HH14 with Atoh1-Gal4 + UAS-tdT and Egr2::GFP (C. left panel, rostral. Right panel, caudal), Hoxb1::GFP (D), Hoxa3::GFP (E) or Hoxd4::GFP (F. left panel, rostral. Right panel, caudal). Scale bars: $50 \mu \mathrm{m}$. G. Diagrams summarising the contributions of Atoh1+/Ptf1a+ progenitors (left panel) or different rhombomeres (right panel) to the medial and descending vestibular nuclei. Scale bars: $50 \mu \mathrm{m}$. H. Close up view of the VeD from an E10 chick hindbrain coronal section electroporated at HH14 with Atoh1::GFP and CAG-mCherry. Scale bar: 100 m. I. Detailed view of Atoh $1^{+}$cells in the rostral VeD. Solid lines, hindbrain border. Dotted line, VeD border. Scale bar: 50 um. J. Close up view of the VeD from an E10 chick hindbrain coronal section electroporated at HH14 with Ptf1a::GFP and CAG-mCherry. Dotted line, VeD border. Scale bar: $100 \mu \mathrm{m}$. K-N. Close up view of the VeD from E10 chick hindbrain coronal sections electroporated at HH14 with Egr2::GFP (K), Hoxa3::GFP (L), Hoxd4::GFP (M) or Hoxb1::GFP (N). Solid lines, hindbrain border (M). Dotted lines, NL borders (K, L and N), NM and VeD borders (M). Scale bars: $50 \mu \mathrm{m}$. 

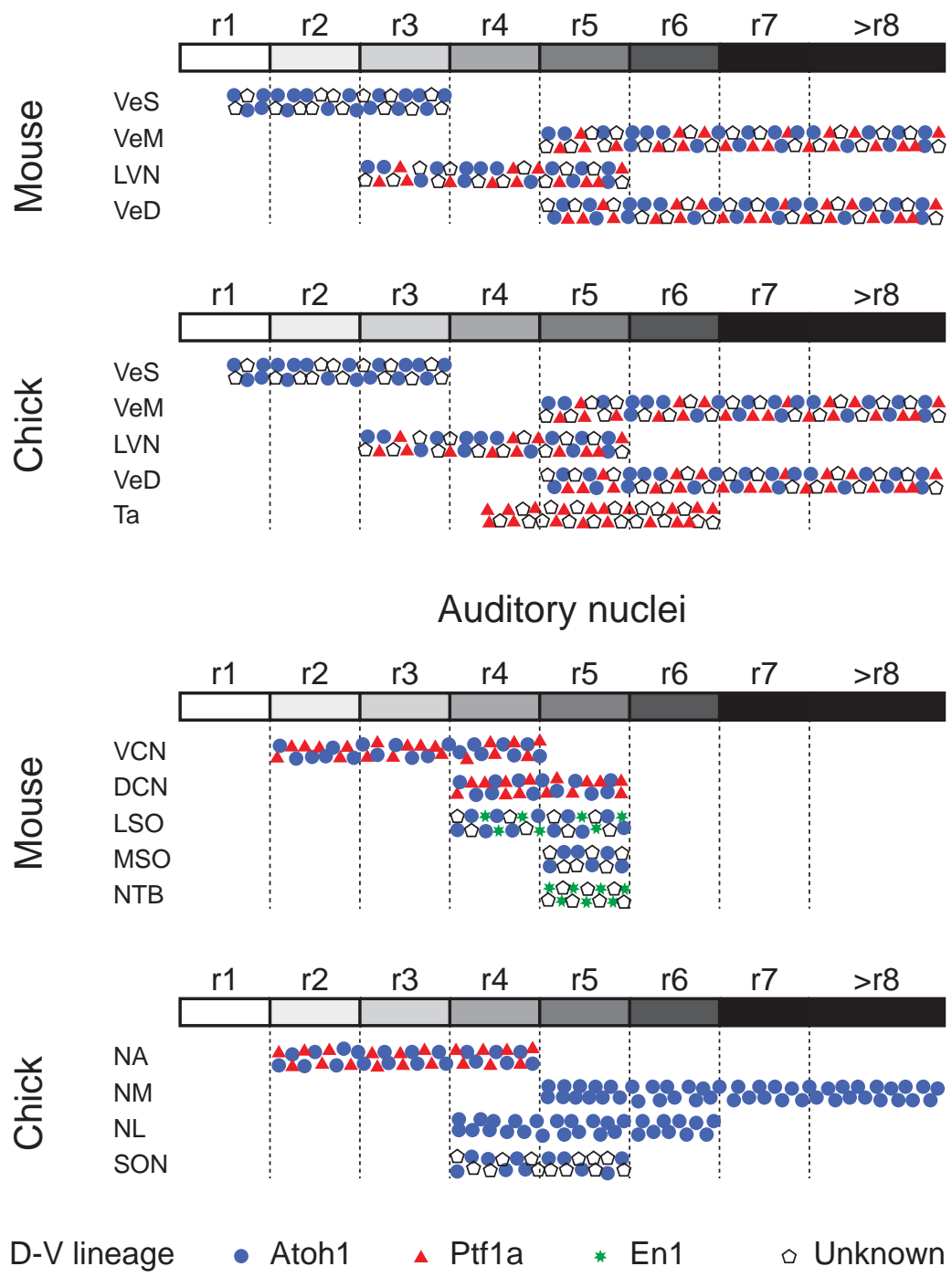

Figure 8. Comparative developmental origin of mammalian and avian vestibular and auditory hindbrain nuclei.

Schematic diagram showing the lineage origin of cells in the auditory and vestibular nuclei (blue circles, Atoh1; red triangles, Ptf1a; green stars, En1; empty pentagons, unknown), alongside their rhombomeric origin (left to right, $r 1$ to $>r 8$, white to black grey scale). Chick mapping data, this work and (Cambronero and Puelles, 2000; Cramer et al., 2000; Marin et al., 2008; Marin and Puelles, 1995). Mouse mapping data from (Altieri et al., 2015; Chen et al., 2012; Di Bonito et al., 2015; Di Bonito et al., 2013; Di Bonito and Studer, 2017; Di Bonito et al., 2017; Farago et al., 2006; Fujiyama et al., 2009; Maricich et al., 2009; Marrs et al., 2013; Marrs and Spirou, 2012; Pasqualetti et al., 2007; Rose et al., 2009; Wang et al., 2005; Yamada et al., 2007). 


\begin{tabular}{lll}
\hline Plasmid & PCR/digest & Restriction enzymes or Primers sequences \\
\hline \hline \multirow{2}{*}{ toh1-Gal4 } & Vector & Ncol + Notl digest of pBatubGal4 vector \\
\cline { 2 - 3 } & Insert PCR & ctccaccgcggtggcAGAGCTTCCACTTCACCTCTCTGAGTG \\
& On Atoh1-Cre vector & gtttcttcttgggcccGGGGAGCGGCGAGAGGCT \\
\hline \hline \multirow{2}{*}{ Atoh1-FLPo } & Vector & Ncol + Notl digest of CAG-FLPo vector \\
\cline { 2 - 3 } & Insert PCR & agcagagcgcggcgcCTCCTGGGCAACGTGCTG \\
& On Atoh1-Cre vector & cctgaggagtgaattggcGAATTCCTCATCAGATCCGCC \\
\hline \hline Ptf1a-Cre & Vector & Ncol + Sacl digest of Atoh1-Cre vector \\
\cline { 2 - 3 } & Insert PCR & gggcgaattggagctAGGATCGTCAGCCACAGAGTTCATGG \\
& On Ptf1a-GFP vector & ctgcagatatccagccCATGGCGCCGCGCTCTGC \\
\hline \hline \multirow{2}{*}{ Egr2-Cre } & Vector & Sacl + Xmal digest of Atoh1-Cre vector \\
\cline { 2 - 3 } & Insert PCR & gggcgaattggagctGGGTTGTGAATGGAGCCAG \\
& On mouse gDNA & attcctgcagcccggGCAAGCCGACCAAACTCC \\
\hline \hline Hoxb1-Cre & Vector & Sacl + Xmal digest of Atoh1-Cre vector \\
\cline { 2 - 3 } & Insert PCR & gggcgaattggagctCTAGTCATCCTTTGTCCC \\
& On mouse gDNA & attcctgcagcccggTCTTGCCCTACAACCTTTC \\
\hline \hline Hoxa3-Cre & Vector & Sacl + Xmal digest of Atoh1-Cre vector \\
\cline { 2 - 3 } & Insert PCR & gggcgaattggagctATCAAATAGCAGCGAATCTTCG \\
& On mouse gDNA & attcctgcagcccggGGGACGTGTAGGAGGTGA \\
\hline \hline Hoxd4-Cre & Vector & Sacl + Xmal digest of Atoh1-Cre vector \\
\cline { 2 - 3 } & Insert PCR & gggcgaattggagctCTAGAAGCCCACAGAAGTTG \\
& On mouse gDNA & attcctgcagcccggCTAGAGCAGGTTCCCAGATG \\
\hline
\end{tabular}

Table 1. Restriction enzymes and sequences of the oligos used for cloning of expression constructs. Uppercase, gene-specific portion. Lowercase, vector specific portion. 